\section{¿Federalismo en Chile? Algunos esbozos acerca de su debate legislativo y su promotor en el siglo $\mathbf{X I X} \mathbf{X}^{\star}$}

Federalism in Chile? Some sketches about their legislative debate and its promoter in the 19th century

\section{Hernán Delgado**}

\section{Resumen}

¿El federalismo en Chile fue una utopía de un hombre adelantado a su época o fue una realidad legal que necesitaba la incipiente nación chilena? El artículo expuesto a continuación revisa la discusión parlamentaria de las ideas político-legislativas impulsadas por José Miguel Infante sobre el modelo federal de Estado, en el Congreso Nacional de julio y agosto de 1826,

\footnotetext{
* Este manuscrito es parte del Proyecto FONDECYT N ${ }^{\circ} 1120012$ : "Élites regionales, elecciones y sociabilidad política", cuyo investigador responsable es el Prof. Dr. Juan Cáceres Muñoz.

Programa de Doctorado en Historia de la Pontificia Universidad Católica de Valparaíso. Universidad de Los Lagos, Campus Osorno, Av. Fuchslocher 1305, Osorno, Chile. Correo electrónico: pedch@ulagos.cl
}

en el Proyecto de Constitución Federal y en algunos números de El Valdiviano Federal ${ }^{1}$ de Santiago de Chile entre 1827 y 1830 . El objetivo que se persigue es evidenciar las relaciones entre una serie de conceptos y proposiciones amparadas bajo la idea del federalismo y las propuestas de Infante en la conformación del Proyecto de Constitución de 1826 a partir de la discusión legislativa de igual año, y la inminente adopción de la organización federal del territorio (que nunca llegaría a ver la luz en Chile), percibiendo si se trató de poner en discusión conceptualizaciones mucho más amplias como el tránsito de pueblos a nación, la representación, la idea de ciudadano u otras semejantes.

Palabras clave: federalismo, Chile, Infante, discusiones parlamentarias, Proyecto de Constitución de 1826, Estado.

\section{Abstract}

Does federalism in Chile was a utopia of a man ahead of his time or was it a legal reality that needed the nascent Chilean nation? Article forth below reviews the parliamentary discussion of political and legislative ideas pushed by José Miguel Infante on the federal state model, in Congress July and August 1826, in the Dra$\mathrm{ft}$ Federal Constitution and in some editions of El Valdiviano Federal of Santiago, Chile, between 1827 and 1830. The objective pursued is to show the relationship between a number of concepts and ideas covered under the idea of federalism and proposed Infante in shaping the draft Constitution of 1826 from the same year legislative debate and the impending adoption of the federal organization of the territory (which never see the light in Chile), perceiving whether

Santiago de Chile. Años 1827-1844. 
it was open to challenge much broader conceptualizations as transit of peoples to nation, representation, the idea of citizen or similar.

Key words: federalism, Chile, Infante, parliamentary discussions, Draft Constitution of 1826, State.

\section{Introducción}

Los sucesos europeos que redundarían en el trance histórico del Antiguo Régimen desde mediados del siglo XVIII junto a los procesos que originarían grandes cambios en el pensamiento y también en los ya consabidos hechos históricos como la revolución francesa, la revolución industrial o la independencia de la América colonial, darían origen finalmente a un Estado liberal que optó por diversas formas de organización político-administrativa: monarquía parlamentaria, constitucional, mancomunidad de repúblicas, imperio, confederaciones, federaciones, congresos generales constituyentes o asambleas provinciales, teniendo en Chile, las últimas tres, un protagonismo fulgurante aunque fugaz.

Las discusiones alrededor de estas nuevas formas de gobierno se dieron en todas las nuevas naciones americanas y, por supuesto, también en Chile. La lucha entre el sistema centralista de gobierno y un sistema federativo fueron la muestra política real o manifiesta de la lucha entre las élites por la mantención de las prebendas y privilegios logrados tras la emancipación versus la ideología liberal que algunos prohombres amparaban para toda la nación y sus provincias de entonces, dando lugar a largos debates parlamentarios y formales, pero también a no menos extensas discusiones fuera de la asamblea nacional, como se daría a través de los distintos periódicos que nacían y morían bajo la reyerta por la posesión del verdadero espíritu republicano al que debía adscribir la construcción del novel Estado-nación chileno.

Estas discusiones basaban sus querellas, entre otras cosas, a partir de la siempre conflictiva materia de la retroversión de la soberanía al pueblo y lo que ello debería traer como consecuencia a los pueblos, dado que su administración debía obedecer a la "voluntad general" de la nación, término complejo y lleno de subjetividades que causaría una serie de dubitaciones a quienes se preocuparían de dar sus propias soluciones a una y otra carencia política y material, las cuales nacían rápidamente demandando remediales inmediatos, pero, así mismo, sustentadas en argumentos que parecían obedecer más a intereses elitarios para todos los nuevos connacionales (Delgado, Gallardo y Lespai 2007; Salazar 2005)², quienes, a su vez, trataban de acomodarse a los permanentes vaivenes de autoridades, de conformaciones geográficas artificiales, y de las conveniencias de los dueños de la tierra y los recursos.

La pregunta ¿qué sociedad se quiere construir en esta nueva república? parecía cada vez menos fácil de responder. Es más, el único acuerdo claro de la élite y de las familias terratenientes

\footnotetext{
La élite, y su lucha horizontal sería la que decidiría el arquetipo político, cultural, social, religioso e institucional sobre el cual la población general debería actuar y tomar partido, cosa que desde mediados del siglo XIX permeó con fuerza en jóvenes como Francisco Bilbao y Santiago Arcos, justamente tras el desprestigio en que cayó el grupo oligárquico dirigente tras escándalos como el del estanco del tabaco (discutido justamente en estas sesiones legislativas de 1826), y sus consecuentes nexos económicos en el poder, pues se entendió que las familias relacionadas también eran parte de la monopolización de la riqueza y del abuso. Además, se hace constar la crisis salarial del ejército que ya había provocado motines sangrientos, como el de 1821 y el de 1826 en Valdivia, Osorno y Chiloé, y que habrían puesto en la cuerda floja la propia independencia.
} 
era salir del colonialismo, sobre todo por los beneficios que les podría deparar la gestión de los negocios e inversiones que podían prospectar en la nueva administración criolla tras el ingente esfuerzo económico de guerra independentista.

En un comienzo, dentro de los sistemas que habían surgido y probado ya otras naciones vecinas, pareció más susceptible de aplicación el modelo de Estado unitario, lo que se vio perturbado por circunstancias prácticas como la extensión del territorio y su consecuente falta de informaciones expeditas, así como lo abstruso del territorio. La fuerza con que los impulsores de la reforma de Estado federal dieron a conocer sus ideas y la claridad sobre cómo aplicarlas al territorio nacional fueron fundamentales para que viera la luz el llamado Proyecto de Constitución [Federal] de 1826 (en adelante PCF) (Congreso Nacional 1889c, tomo XIV: 75$85)^{3}$, así como otras instrucciones legales como el Reglamento provisorio para el régimen de las provincias entretanto la Constitución general se discute, y aprueba en el Congreso, se ecsamina después por las mismas Provincias, y siendo aceptada dictan éstas la particular de cada una que deba regirles en lo sucesivo (en adelante RPr, Infante 1827). Desafortunadamente, las disensiones internas, los tránsfugas políticos liberales ${ }^{4}$, y los intereses velados de las parcialidades familiares, dinamitaron desde dentro al nonato futuro modelo de Estado, no volviendo nunca más a echar raíces en el árido terreno del centralismo republicano.

Esta moción fue presentada explícita y formalmente bajo la presidencia de Diego Antonio Elizondo, en la sesión 133 del 2 de diciembre de 1826, anexo 104. Proyecto de Constitución Federal de 1826 (queda en cursiva solamente el nombre que aparece en el original redactado por el diputado Infante y que, a la época, se sobreentendía que hacía alusión a la futura Constitución Federal de 1826).

Como Manuel José Gandarillas y Diego José Benavente, por ejemplo. Ambos ministros del presidente Ramón Freire pasan del bando liberal al conservador.
Empero, la caída de esta nueva forma de organización político-administrativa no sólo tendría su origen en el seno del Congreso Nacional, sino que también al interior de las propias provincias que eran objeto de debate. Así, los pueblos o provincias no estuvieron exentos de las luchas de poder manifestadas en las elecciones de gobernadores de partido, de provincia e intendentes, de curas párrocos, de alcaldes, o en función de la competencia legislativa que se les quería hacer competer a las asambleas provinciales e, incluso, alzamientos militares como el sucedido en la provincia de Valdivia a raíz de una serie de equívocos y malas comunicaciones, así como la pauperización material de los habitantes de la "frontera de arriba", al decir de María Ximena Urbina (2009). En definitiva, ¿serían estas mismas provincias (Coquimbo, Concepción, Valdivia) las que rechazarían las leyes federales nacidas en 1826 y fenecidas un año después, o bien las discusiones parlamentarias decidirían -convenientemente- hacer pensar que eso había ocurrido así? ¿Realmente las discusiones legislativas de 1826 propendieron al aseguramiento del federalismo como modelo de Estado, o sólo se trató de una estrategia política que llevaría al fracaso del mismo? ¿Qué otros conceptos surgieron en las discusiones a propósito del federalismo?

Según Maximilian Weber, el Estado se habría desarrollado con la modernidad capitalista que habría tenido sus pilares en la ciencia moderna (desarrollo tecnológico), en el capitalismo (mercantil a industrial), y en la conformación misma del Estado (desde la monarquía absoluta hasta el Estado democrático) (Cit. en Sotelo 2004). De hecho, cuando Weber se pregunta por la legitimidad de la dominación arguye que los intereses particulares que preponderarán en una situación de dominación, sólo obtendrán legitimidad cuando sean interpretados por los 
miembros de la sociedad como si constituyesen intereses generales. Por lo tanto, toda dominación legítima, tanto en sus procedimientos como en sus objetivos, debería orientarse a concretar estos intereses generales, materiales o no, para el grupo social (Cit. en Fleet 2009), excluyendo lo que no favorecería esta nueva construcción social abstracta que, por lo que se verá, es lo que se intentó hacer con las provincias en el naciente Estado chileno mediante el federalismo. Esto, al parecer, generaría más problemas que soluciones, lo que haría dudar de la legitimidad del gobierno y de sus intenciones o no de perpetuarse en el poder tal como las monarquías o los gobiernos autoritarios.

Sin embargo, la legitimidad de la dominación está finalmente sustentada en cuestiones axiológicas, culturales o de consenso social. Independientemente de si se está de acuerdo o no con el sociólogo y jurista alemán, quien concebía al Estado como la comunidad humana que dentro de un territorio aspira con éxito al monopolio legítimo (Sotelo 2004) para ejercer los medios de coacción y violencia al interior de la sociedad, se puede vislumbrar la problemática en la que la sociedad española y americana se vieron imbuidas por las tensiones que provocaban las luchas políticas que oscilaban constantemente y hacían peligrar las ya limitadas libertades civiles. Tras esto el poder emergería como vasija de unidad e innovación, en virtud de lo cual los sectores desfavorecidos o menos afortunados serían capaces de movilizarse en pro de la apertura del sistema de dominación de turno, con la esperanza más que razonable de que no se volvería sobre el camino del autoritarismo.

Cuando se debilita la monarquía como sostenedora de la soberanía del Estado, ésta se filtra hacia la nación, la que ya no se compone solamente de individuos, sino que de ciudadanos, o sea, portadores de derechos y deberes políticos, herencia de la revolución francesa de 1789. Éste fue el caso en el que se encontraron los ciudadanos de las distintas provincias chilenas en la mitad de la década del veinte durante el siglo XIX, exigiendo, evidentemente, los derechos políticos que creían tener respecto de tomar sus propias decisiones, especialmente en lo que dice relación con el aspecto económico.

Ahora bien, en cuanto a la definición misma de federalismo en Chile, hay que precisar que para cada nuevo Estado-nación que se había independizado en América, era un concepto peculiar y concordante con los matices propios de ese territorio político-administrativo, aunque, eso sí, con algunos elementos en común que lo conformaban, por ejemplo, la idea de república, de orden, de progreso y de libertad (económica y política), la que no se alejaba mucho del modelo unitario o centralista de Estado en esa época. De igual manera, y tal como lo expone Carole Leal Curiel (2009), el concepto de federalismo siempre va de la mano con el término federal en cuanto organización de Estado, así como también van unidos los conceptos de federación y confederación, por lo que incurrir en una definición única para cada colonia independizada sería infructuoso. Sin embargo, las particularidades de cada una de ellas sí permiten tener en consideración algunos elementos que ayudan a delinearlo. En todo caso, su uso recién se masifica tras el cabildo abierto de 1810 en Chile, entendiendo que con antelación dicha conceptualización había sido evitada dada la situación política predominante de la monarquía española.

Para hablar de federalismo al menos hay que tener en consideración la existencia de dos niveles de gobierno (Paredes 2013), que vendrían 
a estar representados por el gobierno con origen en la capital de la república y los gobiernos provinciales, además, donde cada uno de éstos poseería instituciones con sus respectivos reglamentos que permitirían la comunicación de ambos tipos de gobierno al interior del novel Estado-nación, y asimismo, establecerían competencias constitucionales delineadas por la propia Carta Magna respecto de las discusiones legislativas del Congreso, tanto en lo político (gobierno de la provincia), como en lo económico (por ejemplo, tesorerías o cajas provinciales), o sea, manteniendo su autonomía en estos ámbitos. Huelga decir que la autonomía de cada uno de estos gobiernos debía ser real y no simulada, porque de lo contrario perdería el sentido de ser un modelo federal de Estado único e indivisible, al decir de Camilo Henríquez o de José Amor de la Patria en el Catecismo Político Cristiano, u otros libelos que fueron los encargados de difundir conceptos como el de federalismo en una población que desconocía ese término, o bien, su ínclito significado.

Durante las primeras tres décadas del siglo XIX, el concepto de federación se usó en las nacientes repúblicas americanas como Venezuela, Nueva Granada, Argentina y Chile, y luego, alrededor de 1830, en México y Brasil. En este sentido, estas nuevas naciones entendieron por federación a la estructura federal, es decir, al lazo existente en pro de un bien superior común (en este caso la estabilidad y el orden político) entre diversas provincias que se unen alrededor de esta causa, pero que conservan su independencia e integridad, así como sus derechos básicos, pero subordinadas a un poder central, semejante a lo que Daniel Elazar (1990) haría converger con el modelo aliancista que visualiza, pero con la idea de un poder difuso concentrado en cada miembro de la matriz, no obstan- te lo indicado por Marcello Carmagnani (1993). En cambio, se entendió por confederación la alianza entre varias provincias o Estados al interior de una república, que mantienen su soberanía con un poder central condicionado por el propio conjunto de provincias integrantes.

\section{José Miguel Infante en la construcción del Estado-nación chileno: El sistema federalis- ta de gobierno}

La importancia de José Miguel Infante Rojas como sujeto histórico en la historia de Chile ha sido poco profusa. Las fuerzas políticas opositoras a su acendrado liberalismo decimonónico lograron obnubilar su figura lo suficiente como para quedar en el olvido cotidiano, cultural y político de sus conciudadanos. Ya lo decía Francisco Bilbao al pronunciar unas palabras -lo mismo que el joven escritor Eusebio Lillo- en el funeral del prócer el 9 de abril de 1844, en uno de sus primeros actos políticos públicos: "¡Antes de pasar los umbrales de la muerte, Infante recibió el bautismo de la inmortalidad!" (Gumucio 2003: 8), en alusión crítica a la negativa de la iglesia católica de esa época de hacerle ceremonias fúnebres $^{5}$. Al decir de Domingo Santa María: "Infante tenía todos los arranques de un tribuno; todo el atrevimiento de un hombre de Estado; todo el celo y tino como abogado, y toda la calma, pureza e ilustración como magistrado" (1853: 212).

Su personalidad política ha sido muy poco estudiada, con algunas pocas excepciones en estudios recientes y antiguos ${ }^{6}$. Tan contunden-

\footnotetext{
A pesar de lo que se señala respecto a las honras fúnebres, existe una oración pronunciada por Fray José Santa-Ana en el templo de Santo Domingo el 3 de junio de ese mismo año, donde, seguramente, estuvo ausente tanto Bilbao como Lillo.

Algunos ejemplos de los autores que tratan a Infante desde ángulos distintos, incluido -casi obligadamente- el propio fede-
} 
te fue su actuación política y su actuar público, que su capacidad intelectual le permitió granjearse rápidamente el respeto republicano de sus contemporáneos, influenciándolos lo suficiente para que promulgasen el RPr de 1826 con el fin de preparar la futura Constitución Federal, lo que, como se sabe, jamás llegaría a ocurrir por una serie de hechos, particularmente del juego político de las élites de aquellos tiempos. Lo anterior hizo que paulatinamente la imagen del gobernante fuera desdibujándose, por lo que el director supremo Ramón Freire Serrano (Salazar 2005) ${ }^{7}$ se decidió a convocar un nuevo Congreso General Constituyente, con la finalidad de darle a la república una nueva Constitución, superando la de 1823.

Este sujeto histórico se instituye a sí mismo como parte de una compleja etapa en la incipiente construcción del Estado-nación chileno, tomando partido por la ideología liberal que había inundado el pensamiento y las ideas de los muy nóveles ciudadanos americanos. No obstante ello, Infante logró cristalizar sus propias ideas a través de la lucha formal en la arena política y legislativa, pues sería elegido diputado en ocho ocasiones desde 1811 hasta 1844 (incluida la diputación por suplencia entre 1824 y 1825) (Infante 1827) ${ }^{8}$. En estas sucesivas la-

ralismo, son: Achondo (2006), Zambrano (1999), Elgueta (1986) y Erlbaum (1964), aunque también hay otros como Valenzuela (2008) y Valenzuela et al. (2003), siendo el más significativo el texto de quien después sería presidente de Chile, Domingo Santa María (1853).

Gabriel Salazar se ha encargado de redimir la figura olvidada en la memoria histórica chilena de este general. En su libro pueden leerse unos párrafos que sintetizan su revisión histórica. Aquí sólo se hará referencia a unas líneas que la resumen, de acuerdo a lo dicho por este autor: "Lo que ha ocurrido y ocurre con Ramón Freire ha ocurrido y ocurre con la que fue su principal preocupación como militar y gobernante: la soberanía ciudadana" (2005: 27).

Es curioso ver a Infante aparecer en su bautizo como diputado el año 1811 con la calificación de realista, según esta misma fuente, lo que parece no tan evidente si se lee el discurso que Infante pronunció en la asamblea del 18 de septiembre de 1810, donde su voz fue conciliadora y, como la mayoría de las veces, muy informada bores parlamentarias, orientó su pensamiento alrededor del federalismo, primero (y especialmente) en las sesiones legislativas del Congreso General de 1826, y luego, seguidamente, en el ámbito público mediante la utilización de la prensa periódica que vio nacer una innumerable cantidad de creaciones, aunque dentro de las de mayor duración en el tiempo se encontró la de Infante: El Valdiviano Federal (en adelante EVF'), con la que luchó en el ámbito público contra sus opositores políticos, pero también contra los detractores del pensamiento liberal al que acendradamente esculpía y daba forma, desde la vehemencia pro federalista hasta opiniones sobre la lotería y el juego, partes, sin duda, de la misma estructura republicana que ayudó a afianzar hasta su muerte, el 9 de abril de 1844, a la que sólo sobrevivió un número más de su periódico.

Así las cosas, ¿qué lucha llevó a cabo que le hizo merecedor de esta amputación histórica? Este abogado inició su carrera política como procurador del Cabildo de Santiago de Chile en 1810, mostrando su apoyo a la causa independentista, y participó activamente en la Junta de Gobierno de 1810. Dentro de los cargos, funciones y acciones que poseyó, ejecutó y realizó prolíficamente, pueden mencionarse algunas como: inspirar la abolición total de la

y estudiada. Para corroborar esta última idea puede verse: Colección de historiadores i de documentos relativos a la independencia de Chile (1910), tomo XVIII, pp. 220-224.

$9 \quad$ Por último, cabe mencionar que sólo se hará referencia a EVF en este artículo por la extensión del mismo, pero los demás periódicos de vida ostensiblemente menos longeva que la de El Valdiviano Federal, y que cohabitaron y discutieron a este último y que también se erigieron como objeto de contraste en lo opuesto y en lo símil son materia de estudios posteriores, pues se encuentra allí la contingencia político-social cotidiana de lo que acaecía en las SCL: El Clamor del Pueblo Chileno, La Clave, El Independiente, El Monitor Imparcial, El Vigía, El Constituyente y El Centinela, aunque también publicaciones anteriores que habrían sido el germen precursor de disputas posteriores: La Aurora de Chile (como se sabe, con Camilo Henríquez a la cabeza) y El Duende de Santiago. 
esclavitud por ley del 24 de julio de $1823^{10}$ siendo senador (Santa María 1853) e incluso con efecto retroactivo desde 1811. De igual modo, Infante fue Presidente de la Junta Superior Gubernativa (Junta Nacional de Gobierno entre el 23 de agosto de 1813 y el 11 de enero de 1814), diplomático en 1814 (lo era en Argentina justo tras el Desastre de Rancagua) (Valenzuela 2008), fue uno de los inspiradores del Instituto Nacional de Santiago, también fue uno de los defensores más encarnecidos de las libertades civiles, cuestionando constantemente las prácticas represivas usadas por el partido dominante conservador, criticando medidas portalianas como el presidio ambulante, y denunciando las pésimas condiciones carcelarias. Como se mencionó, fue senador y diputado, también fue presidente del Congreso Nacional, periodista, colaborador tanto de Manuel Rodríguez como de Bernardo O'Higgins, en este último caso como secretario accidental de hacienda y luego como ministro en 1818, y una vez abdicado O'Higgins integró la junta gubernativa que le sucedió, fue redactor del RPr de 1826, así como de otras iniciativas legales, etc.

Tal vez por todo lo anterior, si bien fue un duro crítico de muchos gobernantes, sus actividades transparentes y públicas sólo permitieron que se le atacara de manera estrictamente pública, política e histórica. Finalmente, como vaticinio de su pronto fallecimiento, en 1843 In-

\footnotetext{
10 El primer intento de los Tres Antonios, a finales del siglo XVIII, no había tenido un buen final. Además la iniciativa presentada por Manuel de Salas sólo aludía a la libertad de vientres, es decir, que el recién nacido en Chile, hijo de esclava, se consideraba libre, aunque también quienes pisaran el territorio chileno, pero la élite adinerada ignoró ostensiblemente esta ley, por lo que la propuesta de Infante fue radical y potente, aunque en Chile los esclavos no hayan superado las cien personas, aproximadamente. Recuérdese que si se considera 1823 como fecha de abolición completa de la esclavitud, Chile fue alrededor del noveno país en eliminarla, pero incluso considerando 1811, recién viene a ser el cuarto tras Santo Domingo, Haití, Francia (que la volvería a implementar) y México, a lo menos.
}

fante fue nombrado ministro decano de la Corte Suprema de Justicia, así como miembro de la facultad de leyes en la Universidad de Chile (Santa María 1853) ${ }^{11}$.

Parece muy lógico entender la pasión con la que Infante protegió y propugnó su ideal federalista (Stuven y Cid 2012) ${ }^{12}$ ya que, claramente, a partir de lo que se desprende de sus intervenciones en el Parlamento y sus enérgicas posiciones políticas lanzadas desde EVF, atacó la tendencia conservadora a mantener centralizada la soberanía (Valenzuela 2008) y la atrabiliaria manifestación del poder de los intereses personales o particulares como co-gobierno en el mando de la nación, lo que no podía permitirse, porque de lo contrario el triunfo sobre el absolutismo monárquico español sólo resultaría ser la primera parte de la tiranía y de la muerte de las libertades civiles que tanto estaba costando ya implementar y -mucho más- mantener en la joven república chilena.

A pesar de ser parte de la cúpula social de la época, Infante, según lo que relata Santa María (1853), permaneció incólume frente a las arremetidas contra sus posturas liberales. Sus ideas, heredadas, seguramente, de su tío José Antonio de Rojas (Guerra 2014) ${ }^{13}$, lector de Voltaire y de los demás enciclopedistas y parte del

\footnotetext{
11 Curiosamente, Santa María indica que para Infante las universidades eran el origen de "ideas espurias", promotoras del "monaquismo y la monarquía", por lo que habría renunciado a estos honores.

12 Uno de los periódicos detractores de EVF, El Centinela, tildó al modelo federal como "aborto infernal" al ser sancionada la ley del 11 de julio de 1826 cuando se aprobó por la mayoría de los diputados este modelo para la nación.

13 Respecto a la figura del tío materno de Infante, José Antonio de Rojas, resulta muy completo e ilustrativo el comportamiento, las representaciones y los juegos de rol que se daban en su época, destacando las cualidades de este "padre" de la independencia que pasó de la pena de traición y de la consecuente muerte, a la heroicidad perenne.
} 
ya mítico recuerdo de "los tres Antonios": Rojas, Ovalle y Vera, fueron trasuntadas no sólo en la palestra legislativa, sino que en el RPr de 1826 y en EVF, por lo que perfectamente se puede decir que si bien la memoria histórica lo ha rescatado apenas, su obra ha perdurado y ha servido para entender las distintas posiciones de grupos políticos con intereses asimétricos en los extremos, aunque similares en sus límites.

Por último, hay que dejar establecido que la influencia o ascendencia de Infante era tan transversal, que incluso estuvo a punto de ser elegido como el primer Presidente de la República. El 8 de julio de 1826 se procede a la elección de Presidente y Vice-Presidente de la República (Congreso Nacional 1889b, tomo XII: $72-73)^{14}$, obteniendo 15 votos (9 en votación libre y 6 en votación secreta), con el $39.47 \%$ de los votos Infante (Bando ${ }^{15}$ Federalista), Casiano Arce Vásquez (Independiente) 1 voto con el 2.63\% de las preferencias, y Manuel Blanco Encalada 22 votos (1 público, 21 en votación secreta) con el 57.89\% (Independiente pro Bando Pipiolo). Se empata la Vicepresidencia entre Agustín de Eyzaguirre y el general Francisco Antonio Pinto (con 9 públicos y 6 secretos). Eyzaguirre sería Vice-Presidente con 2 públicos y 20 secretos.

\section{La propuesta legislativa (en sala) y su con- secuencia: EI Proyecto de Constitución Fe- deral de $1826^{16}$}

Las leyes federales fueron dictadas, discutidas y sancionadas en primera instancia entre julio y

\footnotetext{
$14 \quad$ Sesión 5, 8 de julio de 1826, bajo la presidencia de José Ignacio Cienfuegos.

15 La denominación de partido se hizo varias décadas más adelante en el sentido que actualmente se le da.
} bre de 1826 . octubre de 1826. Por esta razón a continuación se hará alusión directa a las sesiones de 1826 (pero específicamente a las discusiones de julio y agosto) por ser el año que se constituyó en la génesis más cercana de lo que sería el régimen federal que trataría de aplicarse sin éxito en la nueva república chilena. Lo anterior no obsta a que se hagan referencias o se extiendan las ideas, preconizadas por Infante en torno al tema, a otras situaciones temporales.

Tras las tensiones manifestadas entre la élite de Santiago y, principalmente, la provincia de Coquimbo, que ya actuaba en un régimen federal de hecho, se mantuvo hasta la creación del Congreso General Constituyente en 1826. Este Congreso, ya transformado en Nacional, tuvo su primera sesión el 1 de julio de 1826, no obstante lo cual, sus primeras actividades, es decir, el llamado a las delegaciones para el envío de sus representantes o diputados se había iniciado el 15 de marzo de 1826 (Congreso Nacional 1889b, tomo XII: 7-13).

Este Parlamento había sido fraguado por el director supremo Ramón Freire a fin de darles una organización legal y lo suficientemente democrática a los pueblos, por cuya denominación se entendería a las "unidades de población e identidad local repartidas a lo largo del territorio chileno, así en el periodo tardo-colonial como en las primeras décadas del siglo XIX" (Fernández 2009: 1163) $)^{17}$.

Freire asumió la idea de la división del territorio nacional en varias provincias (de las tres inicia-

\footnotetext{
$17 \quad$ Como se puede apreciar, ésta es una acepción moderna del término, pues desde finales del siglo XVIII el vocablo aludió a connotaciones negativas, en oposición a lo relevante y excepcional, pero a principios del siglo XIX, cobró realce, pues descansará en ellos "la función soberana de construir y defender la nueva legitimidad soberana".
} 
les se pasó a ocho en un principio, nueve más tarde y ocho nuevamente, según se aprecia en las Sesiones de los Cuerpos Legislativos, en adelante SCL), dando por sentado, informalmente, su intención de democratizar de manera popular la representación de los distintos pueblos. Por esta razón, una vez elegidos los diputados propietarios y suplentes, e instalados en la palestra los primeros, la discusión se centró rápidamente en cómo dar forma a la idea de régimen federal.

En otros términos, los pueblos otorgaban representatividad y, por tanto, legalidad al gobierno central, lo que, a su vez, permitió el afianzamiento de la coacción a manos del régimen del momento, lo que no es menor si se piensa que el orden ${ }^{18}$ fue uno de los adalides más pronunciados por los intelectuales liberales o conservadores de casi todo el siglo XIX, así como la erección de instituciones que preservaran la legalidad traducida tanto en deberes y derechos de los pueblos. Es más, dentro de las mutaciones del concepto pueblos, este mantenimiento del orden se asoció a un gobierno fuerte, centralizado y que simbolizara la unión del pueblo, justamente lo que no habría representado el federalismo al otorgarle poder de decisión a pueblos que carecían de la madurez suficiente para asegurar dicho orden, tal como Camilo Henríquez o el propio José Miguel Infante sinceraron en algún momento.

Esta legalidad de los pueblos -asimilados a las provincias- sería la que tuviese en mente José Miguel Infante para darle sustento a su creación y justificar la autonomía de ellas, al menos en los ámbitos más relevantes según su crite-

$18 \quad$ Como quedará, por ejemplo, claramente plasmado en e lema de la bandera brasileña: "Ordem e Progresso", propio del positivismo y evocando reducidamente la idea del francés Auguste Comte. rio, a saber: en el cuerpo legislativo propio, en sus tribunales de justicia, en la elección de sus gobernadores, de sus curas párrocos e incluso intendentes (aunque discutido), así como en la administración de sus riquezas, teniendo en claro, eso sí, la idea de nación y las necesidades que ésta debía satisfacer en virtud de sus provincias. No obstante, la falencia del término pueblos con el concepto pueblo, consiste en que este último manda a la vez que le ordenan, a diferencia de los primeros que sólo mantenían la primera característica.

Una de las voces que escuchaba Freire era la de José Miguel Infante, promotor irrestricto del régimen federal de gobierno en Chile. La confianza depositada por Freire en Infante se manifestó en su designación de ministro y de presidente de la comisión que Freire dejó a cargo del gobierno cuando partió en su expedición para conquistar Chiloé, último bastión monárquico español en la república.

Una vez elegido diputado por Santiago entre 1826 y 1827 (Infante 1827), Infante sería la voz activa y altisonante del Congreso Nacional, secundado por una serie de sujetos que han pasado también al olvido histórico revisionista, pero que, seguramente, más pronto que tarde, serán reconsiderados. Entre aquellos puede contarse a Manuel Aniceto Padilla (Barros 2005, Congreso Nacional 1889c, tomo XIV: 47$48)^{19}$, y a los diputados Juan Fariña (clérigo), al sacerdote Diego Antonio de Elizondo Prado, al

\section{9}

En el caso del cochabambino Padilla, cabe decir que si federalismo, Padilla fracasó en prácticamente todas las acciones en conjunto que realizó, además de transformarse en un sujeto intrigante $\mathrm{y}$, si bien participó en hechos históricos de diversos países, en muchas de las nuevas naciones en las que intervino de alguna u otra forma fue expulsado o arrestado, incluso en Chile alabando y luego acusando a Bernardo O`Higgins, por ejemplo. 
futuro obispo José Ignacio Cienfuegos Arteaga, al agricultor y posterior diputado por Osorno Francisco Ramón de Vicuña Larraín, al abogado José Silvestre Lazo, al ministro de Freire y abogado Joaquín Campino, etc.

Se eligieron 56 diputados titulares y 49 suplentes, de quienes la mitad eran pro federalismo ${ }^{20}$, gracias a la "propaganda" hecha por Infante (sectores políticos de influencia y capa social alta) y Padilla (sectores modestos de la población, económicamente hablando), por lo que no debió extrañar la rápida acogida que tuvo y la ausencia de sorpresa que se concitó en la sesión $3^{\mathrm{a}}$ del 6 de julio de 1826 (presidida por José Ignacio Cienfuegos): "Se leyó la moción del señor secretario [diputado] Fernández, para que la República de Chile se constituya por sistema federal. Varias declaraciones la pusieron de facto en discusión, i declarada por primera, se mandó traer para el día siguiente a segunda hora" (Congreso Nacional 1889b, tomo XII: 53).

Más allá de lo que pudiera decirse, por ejemplo, de provincias como Concepción o Valdivia en cuanto a su interés por el sistema federal, quedó patente, especialmente en las discusiones de julio y agosto de 1826, que la provincia de Coquimbo aparecía como la más proclive a dicho modelo de Estado y sus diputados se perfilaron como quienes más abogaron por él. Interesante es leer las Instrucciones (Congreso Nacional 1889b, tomo XII: $29-30)^{21}$ que la

20 Sólo para tener en cuenta a algunos diputados no federalistas (conservadores o liberales -y no significa que sean unitarios necesariamente-), a partir de la lectura del tomo XII pueden mencionarse a: Juan Egaña, Diego José Benavente (era liberal y se cambió de bando cuando era ministro de Freire), José Gregorio Argomedo y Luís de la Cruz.

$21 \quad$ Instrucciones que ministró la asamblea de Coquimbo a los diputados de la provincia en el Congreso Nacional que se reunió en la ciudad de Rancagua el 15 de junio de 1826. Esta moción fue presentada explícita y formalmente bajo la presidencia de José Ignacio asamblea coquimbana encomendó a aquéllos, a pesar de que, como se verá en las páginas subsiguientes, no siempre pareció una defensa tan ardorosa y diáfana.

En este sentido, en sus tres artículos numerados más el último, esta asamblea mandató claramente a sus representantes, amenazándolos incluso con el juicio de residencia (Art. 3). Asimismo, con ello quedó en evidencia el poder provincial, al prescribirse que, para que sea válida legalmente, la nueva constitución (permanente o provisoria) debía "primero ser revisada por las actuales asambleas $u$ otras nombradas por las provincias al efecto, y sea aprobada a lo menos por las dos terceras partes de las legislaturas provinciales" (Art. 2), "con tal que siempre se conserve la omnímoda igualdad de derechos entre las provincias" (Art. 1). Lo indicado en el Art. 2 podría hacer recordar lo sucedido en Argentina en lo que respecta al mandato imperativo, lo que iría más allá del voto representativo, es decir, "los poderes e instrucciones son los instrumentos a través de los cuales los diputados se convierten en apoderados (...) de quienes los confieren" (Chiaramonte et al. 1995: 36), sin posibilidad de alterar de mutuo propio este mandato.

Esa misma conciencia fue la que indujo a las tres asambleas mencionadas a mantener no sólo una autonomía política relativa sino también de paridad con respecto a Santiago (Salazar y Pinto 1999). Esto queda esbozado implícitamente, aunque no concluido, en EVF $N^{\circ} 8$ del 2 de febrero de 1828, tras la renuncia de Infante a la Honorable Asamblea de Aconcagua el 27 de febrero de $1827^{22}$. Esto último, debido a for-

Cienfuegos, en la Sesión $1^{\mathrm{a}}$, preparatoria del 1 de julio de 1826, anexo 35.

22 Lo anterior no ha podido ser corroborado aún con los ante- 
mas implícitas y permanentes de exclusión de las provincias según los editores de EVF, como las que constituyen la escasez de fondos con que cuenta cada provincia, su abandono, la inacción de las autoridades centrales y el abuso en la remisión de presidiarios a algunas de ellas, por ejemplo a Valdivia (EVF $N^{\circ} 7$ del 23 de enero de 1828). Fuera de ello, los ataques por parte de los periódicos santiaguinos hacia la capacidad de ilustración y organización de los pueblos al denominarla "masa estúpida"23 (EVF N ${ }^{\circ} 8$ del 2 de febrero de 1828) o "imbécil multitud, estúpida masa de colonos españoles, meros autómatas que no saben ni quieren pensar" (EVF No 9 del 13 de febrero de 1828).

Más adelante Infante propondría la idea de que cada provincia pueda escoger $u$ optar o no a un sistema federal, aunque el sistema mayoritariamente elegido sea el unitario. Lo indicado en el Art. 2 antes mencionado se condice fehacientemente con lo expresado por el PCF, ideado y liderado en la respectiva comisión por Infante, en las Disposiciones Generales, Capítulo 15, Sección $2^{\mathrm{a}}$, Art. 143, dejando abierta la posibilidad del juicio de residencia a todo funcionario público, claro que dejando el detalle a una ley particular que nunca verá su materialización.

En cuanto a lo señalado sobre el representante de Cauquenes (que correspondería a la sexta provincia del Maule) (Congreso Nacional 1889b, tomo XII: 243$)^{24}$, diputado Francisco

cedentes y la biografía de José Miguel Infante que se manejan hasta el momento.

$23 \quad$ Esto probablemente fue de la mano con el rechazo que Infante publicó contra el arribo desde Inglaterra de Andrés Bello (encono que seguirá en el tiempo), arguyendo que en Chile existía una masa de intelectuales que no ha contado con el impulso necesario por parte del gobierno central. Esto lo escribe en el EVF $N^{\circ} 28$ del 30 de julio de 1829.

24 Sesión $24^{\mathrm{a}}, 27$ de julio de 1826 , anexo 274 , bajo la presidencia de José Ignacio Cienfuegos. Cabe señalar que dentro de las discusiones respecto al número de provincias y sus divisiones, se de-
Fernánde $z^{25}$, pro federalismo también, se decía que presentó un proyecto para que la República de Chile opte por el sistema federal, girando en torno a esta propuesta conceptos como unitarismo, federalismo, democracia, república y que, constantemente, emergerían como argumentos de uno y otro bando, concretamente en cuanto a la noción de república y democracia, además de la de representación. Se aprobó por 14 votos a favor y dos en contra. El 14 de julio de 1826 el Ejecutivo lo promulgó como ley de la república ${ }^{26}$.

Lo que provoca esta moción de Fernández fue una discusión muy relevante, no sólo sobre el modelo de organización de la república, sino que también sobre los efectos colaterales que irían de la mano con este régimen: asamblea provincial ${ }^{27}$, intendente, curas párrocos, senadores, diputados y otras autoridades también elegidas vía votación popular, dejando la decisión de continuar o modificar esto último, pero ¿qué tan popular sería? Se verá más adelante que el significado de la época era menos ambicioso del que se percibe y se entiende por éste en la contemporaneidad. Respecto a las elec-

\footnotetext{
rivó de 3 a 8, pasando por 9 provincias, para quedar, definitivamente, en 8 . Esto en relación con el PCF de 1826 de Infante.

$25 \quad$ Sin muchas referencias, parece tratarse del sacerdote Francisco Fernández Díaz, diputado propietario de El Ingenio en las asambleas provinciales de 1826 .

$26 \quad$ Ese mismo día el diputado Bustos propuso la elección de los curas párrocos en cada provincia, lo que pasaría a una comisión eclesiástica que vería el tema. No se ha profundizado en ello en este manuscrito, pero sería interesante conocer los argumentos que se dieron en pro y en contra, considerando la diputación que ostentaban en ese momento varios sacerdotes católicos, incluido el presidente de la sala José Ignacio Cienfuegos.

$27 \quad$ En este sentido, la asamblea provincial de Aconcagua, a sabiendas de Infante, se proclama autónoma "por no existir autoridad nacional legislativa", y se queda con el producto de los impuestos. Esto fue reprimido por el gobierno central de la capital. Este dato en concreto se encontró en un documento de cinco páginas sin autor ni datos editoriales o de algún otro tipo, sólo con la seña timbrado de
} documento: 00041. 
ciones populares o las asambleas, los Arts. 36 del Título $8^{\circ}, 34$ y 33 del Título $7^{\circ}$ del $\operatorname{RPr}$ (19 de enero de 1827), en orden inverso, explicitan en mayor o menor medida la idea que se tenía de las elecciones de parte de estas autoridades. No obstante ello, en el caso de los diputados para las asambleas provinciales, las elecciones populares quedaron claramente establecidas en el Art. 6 de este mismo RPr, el que, a su vez, aludía a la Ley del Congreso expedida el 17 de agosto de 1826, especialmente lo que prescribe su Art. 2 (Congreso Nacional 1889b, tomo XII: 376) ${ }^{28}$.

A propósito de ello, Infante indicaba que el federalismo traería prosperidad y evitaría el despotismo (Congreso Nacional 1889b, tomo XII: 56-57 ${ }^{29}$, así como la elección vía voto de gobernadores, curas párrocos y otros empleados ${ }^{30}$, pues, en el caso de los empleados políticos, argumentaba que si era importante la confianza depositada en ellos a través del voto (en lo externo), con mayor razón debía serlo a la hora de elegir a los párrocos que velarían por el "interior" de sus votantes. En este punto se aprecia cómo, a pesar de la aparente actitud laica de Infante en su vida personal, creía relevante regular la elección de curas párrocos, quizás por la evidente imposibilidad de eliminar su función y ejercicio, porque ello habría atentado directamente sobre las personas (abrumadora y mayoritariamente católicas de las provincias $\left.{ }^{31}\right)$, y

28 Sesión $43^{a}, 17$ de agosto de 1826 , anexo 477 , bajo la presidencia de Diego José Benavente.

Sesión $3^{a}, 6$ de julio de 1826, bajo la presidencia de José Ignacio Cienfuegos.

$30 \quad$ No se especifica en este momento, pero, al leer el PCF se colige que alude a senadores, diputados y ministros de la corte suprema (no así, curiosamente, a los jueces departamentales que fueran nombrados por el Ejecutivo).

31 A propósito de ello, Infante mantuvo presente en su Art. 5 del PCF lo siguiente: "La religión del Estado es la Católica, Apostólica Romana: la nación reconoce un deber en protegerla por leyes habría sido negativo para la aceptación de una forma de organización federal. No obstante lo anterior, lograría hacer predominar la elección popular ante la designación oficial, lo que ya, en sí mismo, era un logro para las libertades civiles y soberanas en las que insistía constantemente este diputado.

En este sentido, el propio presidente del Congreso General Constituyente, José Ignacio Cienfuegos $^{32}$, en la sesión del 6 de julio de 1826, demostraba tanta convicción y confianza en la forma de Estado federal, que a mediados de 1826 en el Debate parlamentario sobre el régimen federal (Stuven y Cid 2012: 442-443; Congreso Nacional 1889b, tomo XII: 56-57) ${ }^{33}$ expuso que estaba muy de acuerdo con:

que el Congreso conceda a los pueblos la elección de supremas autoridades y todas las demás. Si a los pueblos se despoja de esta autoridad se les hace un agravio usurpándoles este derecho. Toda autoridad, inclusive el Jefe de la Nación, debe ser elegida por los pueblos (...) que cada provincia reúna su asamblea y determine las cosas necesarias y convenientes a lo interior y económico de cada una.

Y respecto al otorgamiento de empleos señaló:

que todo empleo lo den los partidos respectivos, y no mantengamos a estas po-

sabias".

32 Congreso Nacional, RBP del sacerdote José Ignacio Cienfuegos Arteaga, diputado propietario por Talca en el Congreso Nacional Constituyente de 1826, del 4 de julio de 1826 al 22 de junio de 1827. Fue presidente provisorio (1 de julio de 1826) y presidente (4 de julio de 1826). Integró la Comisión Permanente de Constitución. Cabe decir también que fue el ideólogo de la ley que permitía la elección por votación popular de curas párrocos, pero fue abolida rápidamente, pues los resultados fueron muy negativos.

33 Sesión $3^{\mathrm{a}}, 6$ de julio de 1826 , bajo su presidencia. 
bres provincias en el estado de miseria y abatimiento a que se hallan reducidas hasta aquí por ser privadas de esa autoridad que les ha costado tanta sangre el conquistarla, y adquirir esa libertad de que hasta aquí no han podido gustar (...). Creo debe existir una caja general, a la que deben concurrir las provincias en proporción de sus entradas, para el sostén de aquellas cosas que pertenecen al sostén de la Nación, y que cada provincia forme su caja provincial para subvenir a sus necesidades particulares, cada una de ellas tendrá igualmente un cuerpo o tribunal de justicia.

Cienfuegos, quien fuera elegido diputado varias veces por las provincias, era claro al reivindicar una serie de derechos que se esgrimirían como fundamento por parte de los partidarios más fervorosos de instaurar el federalismo como organización político-administrativa. Es así como invocó la autoridad propia que en derecho debe investir a los pueblos, relevando la institución de la asamblea como la encargada de velar por la autonomía interior y económica de las provincias, y como el único medio que sostenga el gobierno republicano (Barrón 2002) ${ }^{34}$, así como

$34 \quad$ Lo que, en virtud de lo que se ha visto, sería algo paradójico si se acepta la diferenciación entre republicanismo y liberalismo, pero que, en sentido amplio, estaría refiriéndose a la república como nación de todos los pueblos. La confusión estribaría no tanto en la diferenciación entre monarquía y república, esta última ansiada tanto por liberales como por republicanos, sino que en la distinción entre republicanos unitarios y federalistas y, más aún, porque estos últimos eran considerados liberales (o radicales incluso) respecto a los primeros. También hay que dejar en claro que la distinción entre liberales y conservadores ha sido echada por tierra (Barrón 2002), dadas sus muchas simetrías y pocas diferencias, esto para decir que habían conservadores (como el propio Cienfuegos) que eran partidarios abiertamente de una organización territorial federal del Estado. Estas distinciones y aclaraciones, todavía en debate, deben ser tenidas en cuenta al momento de acercarse a este tipo de estudios, porque si ya no es sencillo hacer referencia a sucesos ocurridos hace casi doscientos años, menos lo es vislumbrar posiciones políticas e intelectuales a través del muchas veces espurio flequillo de la historia. la designación de los empleos importantes (que se hacía impositivamente desde el centro), y la disposición de los recursos que tenga la propia nación, pero, más relevante todavía, para la propia provincia. Por último, arguyó la necesidad de la creación de tribunales de justicia que, dentro de su jurisdicción, vieran las causas que les correspondiesen.

En la sesión del 7 de julio de 1826 (Congreso Nacional $1889 \mathrm{~b}$, tomo XII: 59$)^{35}$, en el punto $5^{\circ}$ de la Cuenta, Infante propuso específicamente que la elección de los gobernadores sea efectuada por los mismos pueblos. Sin embargo, con antelación a esta sesión, en la sesión ordinaria del Congreso Constituyente del 24 de noviembre de 1823 (Congreso Nacional 1889a, tomo VII: 461$)^{36}$, en la exposición que hace la Comisión de Constitución al presentar su proyecto al "Soberano Congreso Constituyente", Egaña (acérrimo opositor al federalismo e interesantísimo rival de Infante) declaró claramente que:

La representación, si no es solidaria, establece el provincialismo, que provoca el federalismo i termina en la anarquía; son tan tristes como repetidos i recientes los sucesos que sancionan esta verdad; cada sección quiere hacer valer separada la soberanía que representa, porque es indivisible, hasta que divididas todas, se anula la soberanía misma.

Al mismo tiempo, Egaña se hacía mérito de la elección censitaria, pues:

\footnotetext{
${ }_{35}$ Sesión $4^{\mathrm{a}}, 7$ de julio de 1826, bajo la presidencia de José Ignacio Cienfuegos.

36 Sesión $60^{\mathrm{a}}, 24$ de noviembre de 1823, anexo 782, bajo la presidencia de Juan Egaña.
} 
El pueblo, decía Montesquieu, es admirable para conocer el mérito i las virtudes de sus principales conciudadanos; pero muchas veces no puede examinar la idoneidad, que necesita verse i esperimentarse de cerca. Por esto es mui conveniente que la facultad que tiene para elejir sus mandatarios, sea dirijida por la calificación de personas ilustradas.

Como puede apreciarse, los puntos de vista (con menos de tres años de distancia entre si), son marcadamente diferentes y dan pie a una serie de interpretaciones y revisiones históricas, teniendo en cuenta la actividad y la postura de ambos legisladores. Sin entrar en el detalle de cada una de sus diferencias, es evidente la utilización de autores similares (Montesquieu) para fundar posturas divergentes, así como la manipulación del concepto de anarquía, usado permanentemente para infundir el terror entre la población y entre los propios legisladores. En este caso, un concepto igual de manipulado y transversal sería el de felicidad, al que se hará referencia en los párrafos siguientes.

Finalmente, la idea de la incapacidad de las provincias de gobernarse a sí mismas, estaría sustentada en la idea de las "pocas luces" de la población, cuestión que, a pesar de ser Egaña quien la manifestó, Infante no parecía rehuirla, pero, grosso modo, él se refiere a la ausencia de instrucción, de establecimientos educacionales ${ }^{37}$, y la falta de profesionales que ilustren a

$37 \quad$ Tal vez inspirado en su tío, José Antonio de Rojas, quien, poseedor de una vasta biblioteca, tenía, entre otros valiosos libros, la Educación Popular de Pedro Rodríguez de Campomanes, ministro de Hacienda de Carlos III de España. El libro se llamó: Discurso sobre la educación popular de los artesanos y su fomento (1775), existiendo un apéndice del mismo año, titulado (brevemente aqui): "Apéndice á la Educación Popular". Aunque el año anterior había publicado Discurso sobre el fomento de la industria popular en Madrid. Respecto al primer libro mencionado, ver Guerra (2014). la población (por lo tanto, la sociedad no tendría las herramientas suficientes para exigir y proveer un régimen democrático), más que a una cuestión natural como hacía mención Egaña. Empero, esta "defensa" que pudiera esgrimirse al pensamiento de Infante, se quebraría cuando, en sesiones posteriores, declaraba que le parecía ridículo que votaran los peones o los campesinos, por lo que resultaría ser una idea extendida en toda la élite gobernante, más allá de sus inclinaciones liberales o conservadoras.

Lo recién indicado, al decir de José Carlos Chiaramonte (1995), se manifestó en varias de las colonias americanas, en el sentido de sustentar la idea de la retroversión de la soberanía al pueblo (extiéndase a los pueblos), aunque ésta fue arrogada por las "ciudades principales" de las Indias, dado que no existía una nación, sino catorce "pueblos americanos" (Lesser 2006: 156). Por esta razón, con el concepto de nación no se estaría aludiendo a una realidad histórica, sino que a un término que podría haberse aplicado a distintas realidades (Estado, pueblo, provincia, soberanía), en función de la calidad establecida por los actores del momento (Morelli 2006), lo que no vendría sino a reafirmar la posibilidad aún en ciernes de optar entre varias formas de Estado, lo que con el tiempo se iría dilucidando para cada Estado-nación en esta región.

La soberanía se expresó conjuntamente en formas disímiles, ya que se manifestó como caudillismo ideológico o como representación electoral, aunque, eso sí, predominó el discurso republicano, prevaleciendo la idea del gobierno representativo en la construcción de los incipientes Estados-naciones americanos como nuevo criterio de legitimidad, lo que no se podía hacer de otro modo, sino invocando al liberalismo como sustrato ideológico y a la ciu- 
dadanía como imaginario. Si bien la ciudadanía filtraba hacia las distintas capas sociales, interiorizando esta concepción, la misma sociedad se encontraba desmembrada internamente, dificultando una implantación de noción identitaria libre de espurias en los hechos (Aljovín y Araya 2005).

Esto también viabilizaría el camino para la instalación de nuevos términos como el derecho a la igualdad, a la libertad, a la representación y participación políticas, disminuir la presión de las vetustas instituciones y, en algunos casos, dinamizar a las provincias ante las capitales, lo cual contribuirá, al decir de McFarlane (2009), al proceso de la construcción de Estados-naciones durante el transcurso del siglo XIX.

En todo caso, todos aquellos legisladores pretendían un Estado sustentado en una república representativa en donde pudieran ejercerse la mayor cantidad de libertades y derechos posibles. Sin embargo, esto tenía sus límites, lo que ya se indicaba respecto a la capacidad de la población de ejercer sus derechos correctamente, es decir, de la "virtud ciudadana" consistente en considerarse ciudadanos y comprender su significado (que no sólo consistiría en ir a votar), lo que haría la diferencia entre el republicanismo y el liberalismo, sobre lo que se habla en las páginas siguientes. Empero, legisladores como Infante sí creían en entregar una mayor amplitud de libertades. No obstante, estar rodeado de una élite pequeña, concentrada en un espacio geográfico centralizado y con ideas muy similares, impidió cualquier concreción real y práctica de un sistema que devenía en inviable mucho antes de su nacimiento.

En este sentido, ser ciudadano conllevaría una actuación para con el Estado, lo que, en pala- bras de Bárbara Silva (Cit. en Pinto y Valdivia 2009), generaría una identificación entre aquel Estado abstracto, de derecho, y el pueblo, es decir, aparecería el concepto de patria. Concepto que, siguiendo los dichos de fray Camilo Henríquez en La Aurora de Chile, contenía un bien superior, comprometiendo la voluntad y el sacrificio incondicional de sus integrantes, sublimando los intereses individuales en pos del bien común, y siendo las leyes las garantes de la libertad civil.

A propósito de lo anterior, a la patria se le da forma y conciencia en América reemplazando el concepto de pueblo, ya que la primera parecía una referencia más amplia y "unificadora" de todos los conciudadanos. Sin embargo, este concepto predominaría principalmente durante el período post-independentista y, más específicamente, el término pueblos, en clara alusión a las diversas partes que estructuraban a la mayor que equivalía a la nación. Ello es relevante en cuanto las provincias adquirirán por única vez (en el caso chileno) una preponderancia notoria y "amenazante" de la estabilidad y el orden logrado tras el triunfo de la república por sobre la monarquía, paradójicamente pretendiendo ese mismo orden y estabilidad.

En todo caso, más que una idea concreta y real del modelo original de organización del Estado, parece ser que el federalismo era, en sí mismo, un opositor -y garante al mismo tiempo- de un retorno de la monarquía o de una tiranía alimentada por su ubicación geográfica. ¿Por qué? Porque el ejercicio de estas libertades que ambicionaba y preveía Infante para el federalismo, implicaba, efectivamente, muchos beneficios, pero que no estaba seguro de conseguir pronto en virtud de lo que arguye en las discusiones parlamentarias. José Miguel In- 
fante Rojas definió el federalismo como: "una forma de gobierno en la que todo cuanto mira al régimen interior de cada Estado o provincia de los que componen la unión, se resuelve y sanciona exclusivamente por sus autoridades provinciales, en la manera que prevenga su respectiva constitución, y los que [¿aceptan?] el interés común de todas por las autoridades generales con arreglo a la Constitución general" (EVF 1828: $\mathrm{N}^{\circ} 13$ ).

En todo caso, más que la contingencia misma del período, la idea de este político consistía en otorgar arras para el futuro, es decir, crear instituciones provinciales que aseguraran las libertades civiles, así como que fomentaran la participación ciudadana con el fin de sentirse parte de la conformación política de la república en ciernes. Por su parte, la mayor propagación de los tres poderes del Estado evitaría el nepotismo y las prebendas, existiendo también una mayor conciencia del rol que le correspondería a la población en el quehacer nacional. Infante tuvo presente la posibilidad de que las provincias se excediesen en el poder que podrían llegar a detentar, trayendo como consecuencia la anarquía. Esto se aprecia nítidamente en la redacción que le da al Art. 133 y $139\left(N^{\circ} 3, N^{\circ} 4\right.$ y $\mathrm{N}^{\circ} 5$ ) del Capítulo 14, Sección $1^{\mathrm{a}}$ : Del régimen provincial perteneciente al PCF de 1826.

Por lo que ya se ha descrito, resulta difícil imaginar una sociedad decimonónica tan empoderada en el uso y práctica democrática. Por eso se mencionó que Infante lo evidenciaba, pero al mismo tiempo trataba de sentar los pilares sobre los que debía construirse ese símbolo de la república moderna. Con seguridad, Infante no pretendía decidir por las provincias, pero lamentablemente se apreciaba en él y en los diputados del bando federalista (que no sola- mente eran liberales, pues, por ejemplo, Cienfuegos era conservador) la guía obligada para los pueblos, es decir, y como lo sintetiza Rafael Gumucio, "todo para el pueblo, pero sin el pueblo" (2003: 17), sentido que redundaba en que sólo las élites eran capaces de garantizar el orden. No obstante ello, tampoco se puede decir que Infante y sus aliados federalistas consideraran esta circunstancia como perenne, sino que trataron de aprovechar las circunstancias ante el temor de devenir nuevamente en un sistema cerrado, rígido, que destruiría la independencia y la futura felicidad de la novel república chilena.

\subsection{El federalismo, los pueblos y la felicidad}

Conscientes los liberales -como Infante- de lo difícil que sería pretender la necesaria participación del pueblo/pueblos en los Estadosnacionales modernos con el objetivo de evitar la constante sombra de la tiranía, se terminan haciendo armónicas las ideas de libertad individual y representación de los intereses del pueblo/pueblos. Dicha libertad sería una sola cosa con la participación, unión natural que Infante veía imposible de aplicar en ese momento, razón por la cual le daría mucha importancia al sistema representativo (federal), es decir, a las personas designadas por las asambleas provinciales, así como a la observancia de las normas legales que debían obedecer dichos representantes, con la esperanza de lograr en años venideros una democracia como desarrollo consciente de la sociedad en su conjunto, puesto que Infante parecía comprender que la democracia representativa constituiría "una realidad elitista, lo que resultaba inconveniente para el desarrollo de las sociedades en procura de su autogobierno" (Mascareño 2011: 186). 
A propósito de la moción del diputado Fernández acerca de que "la República de Chile se constituía por el sistema federal", el diputado Lazo $^{38}$ insistió en su conveniencia arguyendo que en muchos países, entre ellos "Norte América" ${ }^{39}$, se trataba del "sistema más justo y racional" que pudiera haberse pensado. Es interesante este punto, puesto que Lazo deja en claro cómo entiende este sistema al asemejarlo a una casa y a su dueño, quien la gobierna del modo que más le convenga, en alusión a las 8 provincias (Congreso Nacional 1889b, tomo XII: 230) ${ }^{40}$ que componen a la "nación" en 1820 , aunque sin la intromisión en los "asuntos domésticos" (eso sí, sin especificar a qué se refería con esto último) por parte del gobierno central. Lazo insistía en que este sistema federal debía ser la base de todas las instituciones chilenas, exponiendo también que "toda la $\mathrm{Na}$ ción se ha declarado manifiestamente en favor del federalismo", por lo que el Congreso "como órgano de la voluntad general" de los pueblos no debía dilatar esta toma de decisión. Expresó todo ello bajo la creencia de que los pueblos serían tan celosos de sus derechos adquiridos que ello impediría que los gobernantes de turno pudiesen usurpar el poder y transformar el gobierno en una dictadura o una tiranía que subyugara las voluntades de estos pueblos (provincias).

En este caso, Lazo tomó una de las argumentaciones de Infante, a propósito de la distribución

\footnotetext{
$38 \quad$ Congreso Nacional, RBP de José Silvestre Laso (aquí con "s") Requena, diputado por Valparaíso en el período en estudio.

Se refiere a Estados Unidos, error que incluso se comete en la actualidad, aunque en este caso podría estar pensándose también en Canadá o México, a pesar de que no se menciona a sus gobernantes, en especial a este último, debido a la forma de Estado federal que allí también imperaba y que estos diputados federalistas alababan.

$40 \quad$ El territorio se divide en 8 provincias. Sesión $24^{\mathrm{a}}, 27$ de julio de 1826, bajo la presidencia de José Ignacio Cienfuegos.
}

de la soberanía y, por ende, del poder. Dicho de otro modo, el federalismo evitaría el excesivo centralismo y que deviniera en una dictadura (se pone como ejemplo la de Bernardo O'Higgins), en una tiranía o, lo que sería peor, en el retorno de la monarquía. Además, por entonces se insistía en el concepto de anarquía, ya que el centralismo (asociado al unitarismo) sería su propiciador al verse las provincias desmerecidas y descuidadas en función de los privilegios que tendría la capital, ante lo cual Infante propone ideas, en su visión sencillas, como que el Congreso Nacional alternara anualmente en las respectivas capitales de provincia (EVF 1829: $\mathrm{N}^{\circ} 29$ ).

También se coligen de dichas discusiones las distintas acepciones, aún con sus fronteras difusas, de conceptos como los de nación y pueblos, siendo esta última una noción moderna del término, debido a que desde finales del siglo XVIII el vocablo aludió a connotaciones negativas, en oposición a lo relevante y excepcional, no obstante, en los albores del 1800 cobró realce, pues descansaría en ellos "la función soberana de construir y defender la nueva legitimidad soberana" (Fernández 2009: 1163). De igual manera, serían los propios pueblos los que tomarían -o no- conciencia de su importancia para construir la nación, ya sea a través de los procesos eleccionarios (aunque precarios), o bien mediante la representación e incidencia en las decisiones de la nueva república (envío de diputados al Congreso Nacional). En todo caso, no hay que suponer que la autonomía equivalía a emancipación o independencia, puesto que el modelo federal, tal como sucedía en EE.UU, significaba tener en cuenta un gobierno federal central que organice e irradie -como una suerte de nodo- los beneficios de esa unión hacia las provincias federadas. 
A propósito de este tipo de conceptos, cabe hacer mención de la noción de felicidad (Congreso Nacional 1889b, tomo XII: 89$)^{41}$ señalada en un caso puntual por el diputado Bustos ${ }^{42}$, quien se refirió al "principio de la felicidad o infelicidad futura de la Nación", por lo que la discusión sobre este sistema debía ser larga y mediante una comisión que redactara por escrito sus ideas, indicó el diputado.

La felicidad/infelicidad de la nación es un tema muy interesante y que, si bien tiene que ver con las representaciones, también tiene alcances prácticos. Tras la independencia de Chile, tres grupos dirigentes quedan a la cabeza: los empresarios mineros, los agricultores y los comerciantes (la "mesa de tres patas"), y serán ellos quienes propongan un proyecto país para poder defender sus intereses, pero también para alcanzar la felicidad de Chile. Para lograr este objetivo de desarrollo se crea el Estado-nación, sustentado en la evaluación hecha a fines del siglo XVIII en torno a su naturaleza fecunda (Pinto Rodríguez 2003) y una población pequeña y de "luces escasas".

No obstante lo anterior, esto desembocaría inexorablemente en la conformación de un modelo de Estado unitario, fuerte y centralizado, con el objetivo de crear sujetos obedientes y leales, que permitiesen crear una nación política y cultural, es decir, con sentido de pertenencia en función de, al menos, tres elementos: del territorio, del pasado común y de ciertas prácticas sociales para que así esta noción de nación sobrepase a los individuos y se aglutine en la abstracción política de la nación con los

Sesión $7^{\mathrm{a}}, 10$ de julio de 1826, bajo la presidencia de José Ignacio Cienfuegos.

42 Congreso Nacional, RBP de Salvador Bustos de Ojeda, diputado propietario por Chillán. gestores -grupos de poder que buscan seguir afianzándolo-, y el agregado social -dominados- que se siente parte de esta construcción artificial (Pinto Rodríguez 2003), poniendo la fortaleza en la educación ${ }^{43}$ y mirando hacia Europa, justamente lo contrario de lo que postulaban estos diputados en la sesión $7^{\mathrm{a}}$ del 10 de julio de 1826, ya que en ella se ensalzaba a Estados Unidos junto a su organización federal de Estado.

El diputado $\mathrm{Cruz}^{44}$ volvería a insistir en el concepto de felicidad (Congreso Nacional 1889b, tomo XII: 89-90) ${ }^{45}$, dando por hecho que esto es lo que perseguiría el "pueblo chileno". Expresó que esta felicidad no tenía que ver con el modelo de Estado adoptado libremente, sino que con las garantías (en alusión directa a la seguridad y a la propiedad) con las que contara la nación, poniendo como ejemplo de naciones desarrolladas a Rusia, Inglaterra y Estados Unidos, y distinguiendo las dispares formas de organización de Estado de cada una de ellas, es decir, desde el imperio absoluto ruso, a la

$43 \quad$ A propósito de esto, es paradigmático ver la incidencia que el texto/ficción tiene en la nación, y la incidencia de la nación en el texto/ficción, particularmente referida al caso del escritor Alberto Blest Gana y el reconocimiento que hizo Victorino Lastarria de su obra, lo que le valió ingresar a la Facultad de Humanidades de la Universidad de Chile. En su discurso inaugural (3 de enero de 1861), titulado "Literatura chilena. Algunas consideraciones sobre ella", señaló que la novela debía desempeñar un papel en el progreso de los pueblos (http://www.anales.uchile.cl/index.php/ANUC/article/ viewArticle/3177). Con él se comienza a fomentar la comprensión y los alcances del ser chileno, lo que evidentemente contribuiría al fortalecimiento de la nación de la segunda mitad del siglo XIX, la que junto con las guerras de ese período insuflaría el aire vivificante que faltaba para terminar de conformar el sentido de nación o, al menos, una parte muy importante de ella. Para profundizar en este punto ver: Texto / Nación. La novela chilena de filiación histórica (siglos XIX y XX), Proyecto FONDECYT 1120693, cuyo investigador responsable es el Dr. Eduardo Barraza Jara y Hernán Delgado el asesor especializado.

$44 \quad$ Congreso Nacional, RBP del general Luis de la Cruz Goyeneche, diputado propietario por Coelemu.

$45 \quad$ Sesión $7^{\mathrm{a}}, 10$ de julio de 1826, bajo la presidencia de José Ignacio Cienfuegos. 
monarquía constitucional inglesa y al modelo federal estadounidense.

Este diputado, por tanto, no creía que fuera lo más importante definirse por una forma federal de Estado o por uno "solidado" (unitario o centralizado) como él le llamaba, sino que se tratase de un gobierno democrático o popular. En este sentido, indicaba que los pueblos debían tener en cuenta, por entonces, un sistema electivo de gobierno y que la Comisión Constituyente viera de qué tipo sería (federal o unitario). O sea, él proponía un sistema popular representativo sin más, es decir, a pesar de la referencia al gobierno democrático, lo que en verdad se buscaba era un gobierno que representase la mayor cantidad de intereses de la población.

En la misma sesión, el diputado Fariña ${ }^{46}$ se sorprendía por el hecho de que se estuviese cuestionando el "sistema de federación", poniendo como ejemplo lo bien que le iba con él a Estados Unidos en contraste con México (en este punto resultaban contradictorias las noticias que cada diputado invocaba en sus argumentos para demostrar si el federalismo se encontraba funcionando o no), y además criticaba a los diputados que parecían comportarse de manera tránsfuga. Fariña resaltaba el rol que tendría el sistema federal, pues serían los pueblos quienes tomarían las decisiones que más favorecieran sus propios intereses, sin temor de la arbitrariedad del gobernante (o poder central), y se verían beneficiados por una mejor administración económica e interna. El diputado agregaba que Coquimbo deseaba el federalismo, pero no había tenido nada de federal

$46 \quad$ Congreso Nacional, RBP del sacerdote Juan Fariña(s) Ugalde, diputado propietario por Coquimbo. En las discusiones parlamentarias se ve siempre muy cercano al ideario de Infante, secundándole sin ser necesariamente obsecuente. por no ser aún, lamentablemente, el sistema adoptado por la República de Chile. Finalmente, Fariña daba a entender que Santiago sacaba provecho de los pueblos (o provincias) para su propia grandeza, en directo detrimento de aquéllos. Como se ve, las argumentaciones de los diputados tendían a tener un fuerte sesgo regionalista, más que autonomista 0 , mejor dicho, anti-centralista, que uno realmente orientado a un Estado federal organizado y con un centro natural o geográfico.

En el transcurso de la discusión, Infante proclamó de lleno el federalismo, arguyendo que los tiranos ya no asolarían la república, y atacando a quienes decían a los pueblos que: "la federación va a producir el desorden, ella nos sumirá en la anarquía y el país se hará desgraciado para siempre". Infante señaló que el modelo federal era el más apropiado para las naciones de acuerdo a los principios sociales ${ }^{47}$ y el más ventajoso para ellas. Además, agregó que las provincias serían independientes (aunque sin especificar en qué o hasta dónde), y que su extensión sería sólo hasta producir el bien (¿bien común? ${ }^{48}$ ), pero, al mismo tiempo, dichas provincias serían dependientes en lo que tuviese relación con los intereses de la nación, dejando con ello abierta esta posibilidad -quizás a propósito-, sin ponerle coto inmediato ni preci-

$47 \quad$ Este punto lo volvió a subrayar cuando hizo referencia a Jeremy Bentham en EVF N 24 del 19 de febrero de 1829, aludiendo a la seguridad como sinónimo del goce de los derechos individuales, es decir, la libertad personal, de industria, la inviolabilidad de la propiedad, la libertad de imprenta, etc. Esto ya lo había plasmado en el RPr, Art. 47, Título 10: De las obligaciones de las Provincias, y lo volvería a mencionar también en EVF № 36 (pp. 3-4) del 22 de junio de 1830.

$48 \quad$ Al parecer se estaría haciendo referencia a la felicidad de los pueblos (= Common Sense (sentido común) = Common Good = Bien Común = Bienestar), lo que, como se apuntaba en páginas anteriores, llevaría al progreso de los pueblos, cuestión que equivaldría a su felicidad, por lo que podría considerarse, en sentido lato, como un préstamo de la idea de bienestar estadounidense. Infante la plasmó sutilmente en el Art. 43, número 3 del PCF de 1826, cuando hizo alusión al "bien estar". 
sar los límites de este concepto tan subjetivo y abstracto.

Infante ofreció algunos ejemplos al respecto, siendo el más interesante aquél vinculado con la administración judicial, específicamente con los tribunales de justicia, puesto que ante el cuestionamiento del financiamiento de los tribunales, señalaba que la ley debía dejar este aspecto al libre arbitrio de las provincias, exponiendo como alternativas el hecho de acudir a tribunales cercanos o a la propia capital, lo que evidentemente implicaba gastos onerosos y una dilatación aún mayor de lo contencioso. Además, en contraposición al modelo de Estado unitario, arguyó que con él se les obligaba a las provincias a recurrir a la capital para solucionar sus contiendas legales, subyugándolas al centro. Al redactar el PCF, Infante retrotraería esta discusión y plasmaría en ella sus ideas políticas (Art. 136), a pesar de lo cual debería ceder ante la realidad material de la nación, en particular en lo prescrito en el Art. 137 del PCF, al reconocer que "por particulares circunstancias, no se pueden plantear por ahora tribunales de apelación". Independientemente de este contratiempo, esto no le impediría hacer explícita su demanda de descentralización en el Art. 7, número 12 del RPr en su Título $2^{\circ}$ : De las Asambleas, y en el Art. 30 en su Título 6 $6^{\circ}$ Del Poder Judicial.

De igual forma, Infante indicó que los demás gastos que los opositores al modelo federal de Estado le criticaban, debían ser asumidos por toda la nación, a saber, la tropa (el ejército), la armada, las plazas fuertes y las demás instituciones u organismos ${ }^{49}$ de utilidad común. Así

$49 \quad$ Infante mantendría la idea de que las provincias contasen con sus propias cajas de administración financiera o tesorerías, autónomas o, mejor, descentralizadas con respecto a las de la capital. mismo, señaló que autoridades como los gobernadores serían designados por las autoridades locales o provinciales en este caso (Art. 36 del $\mathrm{RPr}$ ). De tratarse de enviados al extranjero, Infante precisó que esto correría por parte del gasto nacional. Siguiendo esta línea, también expresó que una parte de las contribuciones o impuestos como el diezmo, la alcabala o el catastro (Cattaneo 2003$)^{50}$ que fueran cobradas en la provincia sería para los gastos de la nación, y la otra parte sería empleada según lo que estimara conveniente cada provincia (no se fijaron montos o aproximaciones de gastos siquiera). Infante involucró en su discurso a favor del federalismo a los diputados de Coquimbo y Concepción, al tiempo que criticó que gran parte de los recursos provenientes de las provincias en esa época -al igual que en la actualidad- se quedaran en Santiago, beneficiándose la capital mucho más que las demás ciudades de las provincias, supeditadas estas últimas al gobernante de turno ${ }^{51}$. El propio Infante ejemplificaba este punto con establecimientos que habrían en Santiago pero no fuera de él: asilos de huérfanos, hospicios, plazas (alamedas), cárceles (casa de corrección), etc. Sobre esto último, Gabriel Salazar (S/F) señala que los teóricos y pensadores del siglo XIX pretendieron entender la pobreza no como un problema social, sino como uno económico por tanto, atingente a las finanzas públicas- y, peor todavía, como un problema moral (Laborde 2008) $)^{52}$.

\footnotetext{
$50 \quad$ Estos impuestos, específicamente el diezmo y el catastro, continuarían cobrándose desde 1835 hasta 1854. En 1855 convivieron los dos primeros impuestos mencionados más el impuesto territorial; desde 1856 a 1860 se mantienen el catastro y el impuesto territorial, y; finalmente, desde 1861 hasta 1895 el impuesto agrícola sería la contribución territorial única.

$51 \quad$ Recuérdese que recién se acababa de elegir, por parte del Congreso Constituyente, al primer Presidente y Vicepresidente de la República, Manuel Blanco Encalada y Agustín de Eyzaguirre, respectivamente.
}

52 Siguiendo esta idea, Miguel Laborde dice que: "Luego de 
José Miguel Infante se proclamó entonces "chileno más que capitalino", y dijo procurar el bienestar general de las provincias y no sólo de una, especialmente cuando expresó preocuparse de la felicidad de toda la nación, volviendo a insistir en esta idea ya proferida por otros diputados, en este caso decididamente orientada al bien común y al progreso. Es más, Infante incluso señaló que cada provincia debía tener su propio Poder Ejecutivo (Art. 4, 19, 20, 21 y 22 del RPr), haciendo una crítica a la centralización excesiva que los gobernantes le habían dado hasta ese momento a Santiago, por lo que su propuesta federal vendría a modificar positivamente esa situación.

\section{2. "El aborto infernal" (EVF 1829: $\left.N^{\circ} 23\right)^{53}$}

A pesar de coincidencias previas, el diputado Cruz no concordaba con Infante, debido a que consideraba que el federalismo era sólo una de las opciones del modelo republicano, haciendo una distinción entre el unitarismo y el federalismo con el sistema democrático. En esta dirección, argüía -en sentido contrario al de Infante- que los diputados de Concepción no votarían por el modelo federal de Estado, sino que por el sistema republicano. No obstante ello, como señala Barrón (2002), hay que decir que en América no sólo pervivió el republicanismo, sino que tam-

la Independencia chilena, la pobreza ya no es un pecado moral en una ciudad cristiana; es una vergüenza social en una sociedad ilustrada. Igualmente inaceptable (...). La pobreza no puede convivir con la civilización" (2008: 165). En definitiva, durante el siglo XIX serían las advocaciones religiosas y, especialmente para la época, la Iglesia Católica, las que asumirían -por sobre el Estado (unitario o federal)- esta expresión caritativa respecto al "cuidado" de expósitos, mendicantes, ancianos, enfermos y, dentro de estas categorías poco edificantes -recién a fines de la centuria del 1800- de los pobres propiamente tales, no obstante las acciones emprendidas por asociaciones mutuales, de socorro, hogares para niñas y niños, escuelas, hospicios, lazaretos, etc., no vinculadas directamente al Estado.

Como le denomina el periódico El Centinela a la intención de federación. bién el liberalismo. Esta acotación es relevante en la medida que, olvidando la vieja disputa conservadora/liberal, sería el primero el que tratase de mantener el orden y el equilibrio entre los tres clásicos poderes mediante un grupo de hombres ilustres cercanos a la virtud -la que "sería injusto pedirle a los pueblos"-, mientras que el segundo se encargaría de defender a los ciudadanos del poder estatal. Además, al primero se le asociaría permanentemente con la institucionalidad gubernativa, mientras que al segundo se le asociaría más con una libertad desde el punto de vista económico. El diputado Cruz agregaba, a nombre de "los que son de mi sentir", que lo único que provocaría el federalismo sería la desunión de la nación, lo que perjudicaría a las provincias que contaran con menos recursos, razón por la cual el federalismo sólo funcionaría con provincias que poseyeran iguales recursos, similar número de población y semejantes condiciones del territorio en cuanto a la capacidad de proveerse de recursos agrícolas, ganaderos e industriales. Cruz añadía también que en un "gobierno unitario, toda la Nación pertenece a las partes", la desigualdad de las provincias era patente, recalcaba. Por último, aseguraba que las ventajas que pretendía tener el federalismo también las poseía el unitarismo.

En defensa del federalismo, el diputado Vicuña ${ }^{54}$ discutió con Cruz mencionándole tres de las naciones que felizmente utilizaban el sistema federal: Estados Unidos (se da cuenta de unos 10 o 12 millones de personas para la época), México (8 o 9 millones) y Guatemala (de una población similar a la de Chile en esos años, aproximadamente un millón de personas)

\footnotetext{
$54 \quad$ Congreso Nacional, RBP de Francisco Ramón de Vicuña Larraín, diputado propietario por La Ligua en 1826, y por Osorno en 1828.
} 
(INE 1835) ${ }^{55}$. Vicuña se sustentaba en personajes históricos célebres como Washington, Jefferson y Adams, ensalzando constantemente como modelo a Estados Unidos ${ }^{56}$. Además, Vicuña agregaba que el modelo unitario de organización estatal sería el que le prohibiría a las provincias nombrar sus propias autoridades, y administrar sus propios recursos que podrían destinarse a educación o a beneficencia; adicionalmente, el modelo unitario les subyugaría económicamente en función de la repartición que se pudiese hacer de los dineros comunes en cuestiones que no favorecerían en nada a los pueblos, poniendo como ejemplo a la provincia de Coquimbo, específicamente respecto a la falta de dinero para su hospital cuando en la capital se gastaba en banquetes $u$ otras suntuosidades. Finalmente, en su opinión, la única forma de poner coto al "Poder Supremo" que igualaba al absolutismo era "asegurar los derechos de los pueblos" a través del federalismo, y aconsejó a los diputados unitarios leer la Constitución de Estados Unidos, la que ya había sido impresa en La Aurora de Chile años antes (haciendo dos alusiones al concepto de felicidad).

Sin duda, la imagen de EE.UU era portentosa y se tenía permanentemente en consideración, especialmente porque en su gestación existió un acuerdo previo sobre el modelo a construir, siguiéndole luego la revolución de la independencia (los hechos se habrían dado de manera inversa a como ocurrió en Chile). Grosso modo, se puede decir que en Estados Unidos se crearía una república independiente con dos modelos en suspenso: federal o centralista y, a su

\footnotetext{
$55 \quad$ Censo que arrojó cerca de 1.150.000 personas.
}

56 Es curiosa la absoluta ausencia de Canadá, pero se comprende, ya que si bien se constituyó como una confederación, se independizó del Reino Unido en la segunda mitad del siglo XIX (1867). vez, esclavista o de trabajo remunerado. Una vez tomadas estas opciones se centrarían en su emancipación. En palabras del propio John Adams (muerto en 1826, año de la creación de las leyes federales en Chile): "La revolución se llevó a cabo desde antes que empezara la guerra" 57 , sustentando seguramente esta aseveración en la mentalidad estadounidense fundada en la autoconfianza, el patriotismo y el amor por la libertad, lo que, siguiendo esta línea discursiva, ratificaría Alexis de Tocqueville al decir que: "La gran ventaja de [los estadounidenses] es haber llegado a un Estado democrático sin soportar una revolución" (Backenkhöler 2008: 2).

Por su parte, el diputado Villagrán ${ }^{58}$ se preguntaba de dónde extraería el dinero, por ejemplo, la provincia de Concepción, pues ni con los diezmos alcanzaba (para fines eclesiales, principalmente), y además se cuestionaba cómo solucionaría este problema el modelo federal, ambas interrogantes relevantes para dirimir por qué forma de Estado inclinaría su voto. En este punto ha de considerarse que la habilitación material de las provincias, como ya se ha señalado, era bastante precaria. Al respecto, Infante argüiría una serie de elementos para asegurar la presencia de recursos frescos en cada provincia, pero, al mismo tiempo, daría a entender que en un principio todas las provincias deberían aportar a la satisfacción de las necesidades de cada una (se pueden tener en cuenta los Art. 138 del PCF, N ${ }^{\circ} 5$ y N ${ }^{\circ} 7$ del Capítulo 14, Sección 1a: Del régimen provincial; Art. 7 , $\mathrm{N}^{\circ} 6$ y $\mathrm{N}^{\circ} 11$; así como los Art. 37 al 44, incluido el empréstito de Londres), cuestión que generó

\footnotetext{
$57 \quad$ "El camino de la independencia". Departamento de Estado de Estados Unidos (www.usinfo.state.gov).

$58 \quad$ Congreso Nacional, RBP de José Antonio Villagrán CastiIlo, diputado propietario por Los Ángeles.
} 
resquemores en los diputados, incluso en los partidarios del federalismo.

Si bien no dio una respuesta directa a la interrogante de Villagrán, el diputado Torres resaltó la capacidad de la organización federal del Estado de oponerse a un mandato tiránico (que es lo que se constituye como la gran salvaguarda que ofrece esta forma de Estado), ya que de no ejercerse en todas las provincias, ellas se opondrían de inmediato. Torres indicó, de igual modo, que la igualdad era lo que unía a las provincias y que era cosa de poco tiempo para que se logre, lo mismo que su incremento poblacional y sus establecimientos (comerciales, industriales, agrícolas, gubernamentales, judiciales, etc.), a diferencia de lo que promovía el modelo unitario, debido a que la despoblación que se le criticaba a las provincias se debía al centralismo de la capital (aunque no lo dijo exactamente con esas palabras) que concentraba todos los "establecimientos" que hacen migrar a las poblaciones de los pueblos por no encontrarse en ellos algo equivalente. Además, los dueños del capital, al trasladarse a Santiago, llevaban consigo a sus dependientes o empleados, por lo tanto, si había desigualdad entre las provincias debía devolverse a ellas sus derechos particulares, dejando que administrasen su gobierno por sí solas, porque sería la única forma mediante la cual lograrían la felicidad y prosperarían en todos los rubros que creyeran más apropiados a su situación, a pesar de que sucediera paulatinamente, evitando que los generadores de trabajo y comercio (y sus dependientes detrás de ellos) emigrasen hacia la capital o hacia el centro del Estado.

Esta falta de respuestas hizo que el diputado Villagrán se inclinara más por el modelo unitario, criticando, de paso, el hecho de que en el futuro las provincias solucionaran sus dificultades paulatinamente, preguntándose qué pasaría entretanto. Tratando de reforzar la inquietud de Villagrán, el diputado Vicuña aludió a la provincia de Concepción, al cuidado de su frontera y a la posibilidad de constituirse en el astillero y el arsenal de la nación. A propósito, Vicuña puso como ejemplo el Estado de Providence en EE.UU, el cual, a pesar de su escasa población (80 a 90 mil personas), logró desarrollarse dado que las provincias mayores equilibraban a las más pequeñas. En esta dirección, también puso como ejemplo a las naciones europeas de Portugal/España. Como se aprecia, estas referencias foráneas son un indicio claro de los modelos que se tenían por entonces, no obstante, como ya se ha adelantado, no parece que se buscara una obsecuencia primitiva, sino que tomar lo que se pudiera aplicar al Estado chileno, teniendo en consideración su particular conformación demográfica y política.

\subsection{Los otros actores. El federalismo ad portas}

En la Sesión $8^{a}$ del 11 de julio de 1826 (Congreso Nacional $1889 b$, tomo XII: 107$)^{59}$ se resolvía lo siguiente: "La República de Chile se constituye por el régimen federal, cuya Constitución se presentará a los pueblos para su aceptación" (prescrita en el Art. 10 del PCF). En el fragmento se aludía a los pueblos como sinónimo de asambleas provinciales, por lo que, sin esta aprobación no existiría Constitución, es decir, las asambleas provinciales debían ratificar o no la posible nueva organización político-administrativa federal ya adoptada de facto, al igual que en el caso de EE.UU, cuya Constitución

\footnotetext{
59 Anexo 113, bajo la presidencia de José Ignacio Cienfue-
} gos. 
debía ser "ratificada por el pueblo de cada Estado" (Velasco 2012: IX). Éste sería uno de los puntos que Infante reclamaría tras el cese del Congreso Nacional en mayo de 1827, respecto a la legalidad de la Carta Fundamental de 1828 $\mathrm{y}$, por lo mismo, de varios de sus artículos (EVF 1829: $\left.\mathrm{N}^{\circ} 29\right)^{60}$. El triunfo fue abrumador: 36 votos $^{61}$ a favor del federalismo, uno por el sistema unitario y otro por el sistema popular representativo democrático (Stuven y Cid 2012: 482) ${ }^{62}$, tal como lo indicara el título mismo del RPr.

No obstante lo expuesto por el Congreso General Constituyente, éste también aclaraba que la soberanía era indivisible, por lo que una vez que se dictase una Constitución se volverían a conformar las asambleas para aprobarla (Congreso Nacional 1889b, tomo XII: 357-358) ${ }^{63}$ : "siendo innegable que la soberanía de la Nación reside en el Congreso mediante los plenos poderes con que están autorizados los diputados que le componen, lo es también que las asambleas provinciales fenecieron con la instalación de este Soberano Cuerpo Representativo". Por lo que se decretaba (Congreso Nacional1889b,

$60 \quad$ Muchos de estos artículos son notoriamente similares al PCF de 1826 ideado por el propio Infante, incluso llegaría a sentirse amenazado por los numerales de la Carta de 1828, por ejemplo, cuando en el Art. 18 se hace referencia a la libertad de imprenta, castigando a quienes abusen de ella sin especificación alguna.

$61 \quad$ Si bien no se atiende este detalle en el artículo, queda la duda respecto de la cantidad de votos, por cuanto los presentes, según el acta de dicha sesión, fueron 37 diputados y los votos 38 (estaba ausente uno de los dos diputados de apellido Arriagada).

$62 \quad$ Las excepciones estuvieron a cargo del diputado Eyzaguirre quien votó por la forma de Estado unitaria, y el diputado Villagrán quien lo hizo por el sistema popular representativo. El diputado Eyzaguirre tuvo una visión distinta, aunque en la misma línea, pues propone hacer dos Constituciones, una unitaria y otra federal (en tono de sorna), pues se trataba sólo de un ensayo constitucional y nada más que eso, pero estaba de acuerdo con que sería una "tiranía" impedir que las provincias se pronuncien por uno $u$ otro modelo y elijan federarse con una $u$ otra provincia.

63 Discusión del proyecto sobre instalación de asambleas, donde se sancionan sus 5 numerales. Sesión $40^{\mathrm{a}}, 12$ de agosto de 1826, anexo 107, bajo la presidencia de Diego José Benavente. tomo XII: 107)64: "no puede haber asambleas provinciales durante el Congreso por ser indivisible la Soberanía Nacional que le constituye; así es que de hecho están disueltas. -Santiago, julio 11 de 1826- Juan de Ojeda".

Las pasiones exhibidas durante las discusiones, en primera instancia, para optar por una organización territorial de Estado unitario o federal, y luego, para fijar su articulado legal, daban pie a la integración de múltiples elementos como los que esgrimía el diputado Lazo, quien declaraba que "este sistema será un antemural contra la opresión" (Congreso Nacional 1889b, tomo XII: 101$)^{65}$, del que nacerán ciudadanos útiles a la sociedad, impulsando la felicidad nacional. Lazo argüía que durante 300 años Chile había tenido un modelo unitario (incluyendo el "despotismo" monárquico y los primeros 20 años del gobierno). Además, contra-argumentaba que no existían hombres preparados para asumir las magistraturas, diciendo que cualquier pueblo, por infeliz que éste sea, debe tener personas que ejerzan el gobierno y los cargos de importancia (EVF 1829: $\left.\mathrm{N}^{\circ} 28\right)^{66}$, pero lo que más se requería era la rectitud, la probidad y la justicia (EVF 1829: $\left.N^{0} 30\right)^{67}$, cualidades que

64 Sesión $8^{a}, 11$ de julio de 1826, anexo 107, bajo la presidencia de José Ignacio Cienfuegos.

65 Sesión $8^{\mathrm{a}}, 11$ de julio de 1826 , bajo la presidencia de José Ignacio Cienfuegos. Lazo hablaba desde lo propio, pues era magistrado, a pesar de que aquí se refería a todo tipo de cargos.

$66 \quad$ Tanto fue así que el propio Infante se mostró crítico ante el arribo desde Inglaterra del venezolano Andrés Bello López, diciendo que en Chile ya existía una masa de intelectuales que sólo requeriría ser avalada y apoyada por las autoridades.

$67 \quad$ Cosa que le preocupaba a Infante en EVF № 30 (pág. 1), del 15 de septiembre de 1829, cuando criticó el Art. 12 de la Constitución de 1828, arguyendo que con él se propendería a la aparición de magistrados déspotas y a hacer esclavos a los pueblos. El Art. 12 de la Carta de 1828 decía: "toda acción que no ataque directa o indirectamente a la sociedad, o perjudique a un tercero, está exenta de la jurisdicción del magistrado y reservada sólo a Dios"; Infante proponía al respecto que para evitar esos problemas se redactase de nuevo: "Toda acción que la ley no prohíbe, está exenta de la jurisdicción del magistrado". 
tendrían los gobernantes que fueran elegidos entre sus mismos pares al interior de las provincias. En todo caso, Lazo daba a entender que la forma federal de Estado no podía ser peor que la unitaria que había gobernado hasta entonces en Chile. Por último, expresaba que las leyes eran mutables y que si el modelo no daba resultados, otro Congreso lo modificaría y así constantemente, según sea la conveniencia y la utilidad para la nación, por lo que no cabía amilanarse ante ese modelo político-administrativo. Además, Lazo proponía que la Ley de Residencia que antiguamente se aplicaba a los capitanes generales de Chile o a sus gobernadores, se aplicara de igual modo a gobernantes, autoridades o empleados públicos en general para evitar la impunidad.

Infante, defendiendo la aplicación del federalismo, concordaba con que ya se habían tenido 16 años de "revolución" (contados, evidentemente, desde 1810) y no se había avanzado sustancialmente durante ese tiempo. Ponía como ejemplo a EE.UU que, en medio de la guerra, logró mantener un Congreso y expedir leyes acordes con su situación y para bienestar general de su población (Velasco 2012) ${ }^{68}$, a diferencia de lo que ocurría en América del Sur. Infante además señalaba que a las provincias les convendría un Cuerpo Legislativo que legislase en función de lo que se ajustara a cada una de ellas.

\footnotetext{
$68 \quad$ Cabe recordar que: "no obstante lo modesto de sus facultades, el Congreso de la Confederación no era respectado ni sus órdenes obedecidas, y aunque los componentes [Estados] de aquélla no habían reasumido su independencia ni disuelto formalmente la unión, sus respectivas legislaturas estaban entregadas a una orgía de medidas inconexas e irresponsables". Además, "las condiciones económicas eran precarias (...)". A partir de estos fragmentos se puede desprender que la situación de Estados Unidos fue complicada, de hecho se le ha llamado el "período crítico de la historia americana", con el fin de comprender que el sólo hecho de declararse federal no significaba esfuerzo o ausencia de dificultades a superar.
}

Infante, a su vez, criticaba a Cruz por insinuar que tenía poderes para oponerse al federalismo, cuando declaró que sólo venía mandatado a votar por el sistema popular representativo, dando a entender que este tipo de mandato era un hecho para los comisionados enviados por las asambleas al Congreso General Constituyente de 1826, cuestión que justificaba la reconvención hecha por Infante. Cruz le rebatiría argumentando que lo único importante era el sistema popular representativo, y que la única diferencia entre el unitarismo y el federalismo era que el primero no tenía cuerpos legislativos, sin embargo, Infante defendería su idea arguyendo que si no existieran esos cuerpos las provincias estarían sujetas para siempre al mandatario, deviniendo con seguridad en una tiranía. Además, le criticaba a Cruz representar a la asamblea de Concepción (venía de Coelemu), cuando ésa había sido la primera en dar el grito de federación, pues junto con Coquimbo eran las provincias que realmente podían seguir el curso natural y geográfico dadas sus condiciones agrícolas y económicas.

En esta misma sesión (Congreso Nacional 1889b, tomo XII: 101) ${ }^{69}$, Eyzaguirre criticó al federalismo porque, a su juicio, no garantizaba nada, poniendo como ejemplo a Coquimbo que parecía ser la provincia más abanderada por aquel modelo-, sin poseer, no obstante, ninguno de los adelantos a los que se aspiraba con dicho sistema: "ni tribunales de justicia, ni casas de corrección, ni hospitales, sólo su instituto (¿...?)". Eyzaguirre declaraba que ni Coquimbo ni Concepción (ya por la guerra, ya por los bandidos) tenían suficientes recursos propios, por lo que no podrían ayudar a las otras provincias -en teoría más pobres-, razón por

$69 \quad$ Sesión $8^{a}, 11$ de julio de 1826, bajo la presidencia de José 127 Ignacio Cienfuegos. 
la cual deberían recurrir a la capital para solicitar recursos. Estas ciudades tampoco podrían mantener su ejército, el que se hacía muy relevante pues ya se pensaba en un enfrentamiento con Perú, por lo tanto, la seguridad nacional se haría difícil en tiempos de guerra, pues los gastos deberían obtenerse sin provenir de las necesitadas provincias, lo que incluso podría provocar disensiones intestinas entre ellas. Según Eyzaguirre, la federación sería la "ruina" de los pueblos, y la "miseria" y la "deshonra" de Chile. No obstante, José Miguel Infante, en su RPr rebatiría implícitamente los supuestos respecto a la milicia provincial en el Art. 8, $\mathrm{N}^{\circ} 3, \mathrm{y}$ en el Art. 20, $\mathrm{N}^{\circ} 10$ y $\mathrm{N}^{\circ} 11$, donde indicaba que ninguna asamblea $u$ otra autoridad provincial podría "tener en tiempo alguno tropa permanente ni buques de guerra sin el consentimiento de la Legislatura Nacional", y así también en lo proscrito por el Art. 43, $\mathrm{N}^{\circ} 13$ del PCF de 1826, respecto a las atribuciones del Congreso Nacional en cuanto a "fijar el contingente de hombres respectivos a cada provincia; y dar reglamentos para su organización y servicio".

\subsection{La defensa de un conservador}

Como se mencionó anteriormente, el presidente de la sala José Ignacio Cienfuegos (conservador) estuvo de acuerdo con el modelo democrático federal, pero no con el federalismo "estricto y absoluto, que en su centro tiene un déspota, cuales son los círculos de la Confederación del Rhin" (en alusión a Napoleón y al protectorado francés impuesto a esta reunión de príncipes alemanes). Cienfuegos manifestó su deseo por un gobierno en donde se gozara de la libertad y de los derechos, por lo que no podría obligarse la división de las provincias, ya que esto sería derecho de cada pueblo, así como la elección de sus man- datarios (en este punto, de acuerdo con Infante respecto a la elección de los gobernadores ${ }^{70}$ y demás autoridades, pero también con Eyzaguirre en cuanto a la libre elección de su sistema de gobierno por parte de cada provincia). También aludió a lo acontecido en las Provincias Unidas del Río de la Plata, pues creía que el "despotismo general" mandó gobernadores a los pueblos (no elegidos por ellos), quienes se sublevaron en contra de dicha "servidumbre", dando como resultado "la guerra civil y la anarquía".

Esta argumentación por negación, si bien era cierta, no constituiría una realidad diferente por el solo hecho de que los gobernadores fueran elegidos en Chile, ya que era imposible pretender que se diera una situación positiva en sí misma por ello, aunque se entendía que se partiría de una base representativa favorable y no de una imposición desde el gobierno central. Así mismo, el propio Infante (Congreso Nacional 1889b, tomo XII: 114) ${ }^{71}$, en respuesta a lo dicho por el diputado Benavente ${ }^{72}$, creyó que era preciso reglamentar las actuaciones de los gobernadores de partido y de provincia para evitar caer en el des-

\footnotetext{
70 En cualquier caso debe recordarse que no todos los gobernadores se elegirían por el pueblo, los gobernadores provinciales de Valparaíso, Valdivia y Chiloé serían esa excepción por tratarse de jefes militares. En las dos últimas se trataría de gobernadores-intendentes, porque al mismo tiempo atenderían lo político y lo militar. Esto se debía a la necesidad de que los jefes militares estuviesen en concordancia con el gobierno central ante una eventual confrontación bélica. A esta excepción, lógicamente, Infante se opondría, dadas las vejaciones y los abusos a los que conducirían estas prácticas. A esto se suma lo que Infante declaraba en EVF Nº 2 (pág. 3), del 11 de diciembre de 1827, al proponer la abolición de este cargo de gobernador-intendente y dar una moción para sustituirlos por presidentes de provincia, elección que harían las futuras municipalidades de cada provincia.

71 Sesión $9^{a}, 12$ de julio de 1826, bajo la presidencia de José Ignacio Cienfuegos.

$72 \quad$ Congreso Nacional, RBP de Diego José Benavente Bustamante, diputado suplente por Concepción entre 1826-27 y propietario por Valdivia entre 1831-34. Fue carrerino, ministro de Hacienda de Freire (1823-24) y apoyó a Portales en su gestión del estanco del tabaco, todo esto entre los numerosos cargos y hechos en los que participó.
} 
orden y en el abuso de libertad de los pueblos, evadiendo, de paso, la anarquía, pero también sorteando otro fantasma: el intervencionismo que podía ejercer el intendente en los gobernadores y sus electores (Guerra 2002), por lo que incluso se pensaba impedir la libre elección a fin de salvaguardar los derechos de los pueblos.

Cienfuegos coincidía también con Infante en que si bien los cabildos no tenían recursos ni jurisdicción, esto podía trocarse por una asamblea u otra similar que tuviese autoridad sobre todo su futuro territorio y se le reservasen sus "rentas" para lograr la felicidad de su población. No obstante, todos estos pueblos debían "estar unidos a la capital" con el objeto de que no "abuse[n] de su libertad", en otras palabras, Cienfuegos daba cuenta con ello de su temor a la anarquía proveniente de la desorganización de los pueblos. Además, indicaba que, a pesar de sus derechos, los pueblos debían estar sujetos a un presidente de la nación, así como, en lo judicial, a un tribunal supremo de justicia. En virtud de ello, su idea consistía en que todos los pueblos tuvieran un juez de letras (para resolver en lo contencioso) y, a medida que fuesen teniendo recursos, su propia Corte de Apelaciones. Lo anterior estaba salvaguardado por lo indicado tanto en el PCF como en el RPr, especialmente en lo referido a la Corte Suprema en el Art. 117 respecto a sus atribuciones $1^{\mathrm{a}}$ y $4^{\mathrm{a}}$ a propósito de las diferencias entre las provincias, o de las Cortes y Juzgados Departamentales de Justicia entre los Art. 120 al 124 del PCF. En el RPr, Art. 20, N 7, Infante velaba por la independencia económica de las provincias, aunque con restricciones inespecíficas que sí se abrían un poco más entre los Arts. 37 al 44, particularmente en el 41 que, no obstante, seguía dejando abierta la misma duda reflejada en las líneas precedentes por su generalidad.
Además, se recalcaba que los empleados debían ser pagados por las cajas provinciales o, en su defecto, por la nacional (incluido el cura con el fin de no pagar por óleos, bautizos, casamientos o entierros). En el caso de uno de los impuestos de la época, el diezmo, debía servir para el "socorro de los pobres" si es que no alcanzaba para un hospital. También se consignaba la idea de crear un instituto de educación (es obvio que parecía ir más allá de una simpe escuela) para que aumentara la ilustración de la población de las provincias. Se hacía referencia, a su vez, a los futuros problemas que podría tener este modelo -como cualquier otro-, pero que, sin duda, sería el que fije la felicidad de la república. De igual manera, se evidenciaba un ataque moderado al supuesto derecho divino de los reyes asemejándose a la tiranía, aunque los gobernantes debían respetar la "ley eterna del Criador", quien quiere "nuestra felicidad", libertad e igualdad.

En virtud de lo indicado, en el $\mathrm{RPr}$ (Art. 7, $\mathrm{N}^{\circ} 3 \mathrm{y}$ $\mathrm{N}^{\circ} 4$; Art. 20, $\mathrm{N}^{\circ} 12, \mathrm{~N}^{\circ} 38, \mathrm{~N}^{\circ} 39$ y del $\mathrm{N}^{\circ} 41$ al $\left.N^{\circ} 44\right)$ se dejaba establecida esta propuesta de normativa, en particular respecto a los empleados quienes seguirían siendo pagados por la caja nacional hasta que el Congreso Nacional dispusiera con precisión qué le tocaría pagar a la caja nacional y qué a la caja provincial. En todo caso, se especificaban algunos cargos como los de intendentes, sacerdotes, senadores, secretarios de asambleas y otros, dejándose incluso la puerta abierta para el nombramiento o la designación inmediata de cargos y empleos que las provincias creyeran indispensables para su eficaz funcionamiento.

Sobre la elección de gobernadores se daría una interesante discusión (Congreso Nacional 1889b, tomo XII: 125-129) ${ }^{73}$ respecto a quiénes

\footnotetext{
73 Sesión $10^{\mathrm{a}}, 13$ de julio de 1826 , bajo la presidencia de
} José Ignacio Cienfuegos. 
podrían votar. El resultado sería el voto censitario, sin embargo, se pasaría desde el requisito de saber leer y escribir al de tener también un capital (de 1000 pesos a 200) o una propiedad equivalente. Se decía que esta discusión era interesante porque más allá de las posturas prácticas, se dejaban entrever las posturas políticas (tal vez se pueda decir de élite) que manifestaban diputados como Benavente, Meneses ${ }^{74}$ e Infante. Benavente creía que exigir saber leer y escribir era "restringir los derechos del ciudadano", pero Meneses alegaba que estas condiciones impedirían el intervencionismo y los engaños o manipulaciones como las ocurridas en las elecciones, confiando ciegamente que ya en 1840 la felicidad (léase en términos de progreso) permitiría que todos los chilenos estuviesen instruidos. Además, consideraba que era muy poca la suma de 200 pesos como exigencia para sufragar y que en ese caso irían "a votar hasta los peones" (j...!), de lo cual se desprende que Benavente pretendía que los caudillos llevasen a su gente a votar no por un espíritu igualitario, aunque esto se podría discutir dado su acendrado y antiguo carrerismo y, claro, su apoyo al federalismo. En la misma dirección, el diputado Bauzá ${ }^{75}$ se preguntaba si los peones no eran también ciudadanos, cuestionándose por qué se les negaban sus derechos, manteniéndolos en "estado de abatimiento". Por ello propuso vehementemente que se le permitiera votar a cualquier hombre en su sano juicio, "vaya con un poncho o aunque vaya en cueros (...). No hay distinción entre los hombres, sólo su buena conducta y sus virtudes", decía.

$74 \quad$ Congreso Nacional, RBP de Juan Francisco Meneses Echanes, diputado propietario por Los Andes, pelucón y ardoroso realista antes de la independencia.

$75 \quad$ Congreso Nacional, RBP del sacerdote franciscano e independentista Juan Antonio Bauzá, diputado propietario por Colchagua.
Por su parte, Infante señalaba, curiosamente, que él no estaba de acuerdo con que se le permitiera votar a todo el mundo, porque con esa "absoluta democracia" sólo se oprimiría más a los pueblos y se favorecería a los "aristócratas". Este diputado pensaba que al consentir que la masa votara, las personas que dominaban los pueblos pequeños se verían favorecidas a causa de la dependencia que tendrían quienes trabajaban para ellos, equiparándolos así a niños que no tendrían juicio ni aptitudes para elegir a quién sería su representante, agregando que "por la misma razón se lo han negado a los que dependen de otros, porque jamás pueden obrar con libertad, que equivale a no tener discernimiento". A partir de ello se puede deducir que Infante apoyaba la exigencia de saber leer y escribir, porque demostrar propiedad o capital determinado podía fingirse, no así la instrucción. No obstante, Infante también proponía que se fijara en mil pesos cualquier propiedad (inmueble, mueble, animales, dinero, etc.) para evitar la manipulación de la aristocracia, impidiendo con ello los desórdenes o embaucamientos. No obstante lo anterior, en el EVF No 2 (pág. 3) del 11 de diciembre de 1827, Infante planteaba como la mejor alternativa llamar a todos quienes pudiesen sufragar, en lugar de convocar sólo a algunos que pudieran estar influenciados por los miembros del cabildo, refiriéndose a la elección de gobernadores.

\section{Para terminar}

Como se aprecia, conceptos como los de anarquía, tiranía, desgobierno, centralismo y abuso de poder son los fantasmas que rehúye el bando federalista. Si bien existió un PCF que reglamentó cada una de las posiciones asumidas en defensa de este modelo de Estado, las discusiones 
parlamentarias de la época parecen demostrar cómo evitar los males que trae consigo la personificación del poder en una persona o en una provincia más que patrocinar los beneficios reales del federalismo, sin desconocer, por supuesto, los aportes que traería consigo dicho modelo.

El diputado Eyzaguirre se caracterizó por proponer preguntas concretas pero válidas, pues a pesar de que todo lo dicho sobre la federación parecía positivo, cabía la interrogante acerca de dónde se sacarían los fondos para financiar hospitales, empleados, instituciones o establecimientos si, ni siquiera en Santiago, con todos los recursos que le brindan las propias provincias, se tenía un hospital ni se tenían al día los pagos de servicios. De allí que el diputado empleara ejemplos negativos como podía ser el caso de la República Argentina, la que se encontraba debatiéndose fratricidamente en una guerra civil cuyo fin aún no era previsible para sus provincias, especialmente San Juan. A su vez, Eyzaguirre criticaba de igual también a EE.UU, arguyendo que si este pueblo hubiese optado por un modelo unitario, habría llegado a ser la gran nación que es actualmente mucho antes que con el sistema federal que adoptó, lo que es discutible, pero comprensible si se recuerda lo trágico y sangriento que fue el tránsito desde el unitarismo al federalismo, teniendo en cuenta, eso sí, las peculiaridades de dicho proceso (Oszlak 1997) ${ }^{76}$.

En la sesión del 15 de julio de 1826 (Congreso Nacional 1889b, tomo XII: 150$)^{77}$ el Congreso Nacional decretó la forma federal de Esta-

\footnotetext{
$76 \quad$ Por ejemplo, era el caso de las Provincias Unidas del Río de la Plata, los políticos y legisladores que tenían intereses ganaderos, agrícolas o de la banca que dependían del régimen de gobierno a establecer, pues en un caso se podía exigir el derecho de aduana del litoral rioplatense y no redistribuirlo, o bien a la inversa.

77 Sesión $12^{\mathrm{a}}, 15$ de julio de 1826, anexos 151 y 152, bajo la presidencia de José Ignacio Cienfuegos.
}

do para el país y creó un proyecto de ley para protegerlo, proponiendo combatir el bandidaje en la provincia del Maule. Más allá del conciso articulado de dicho proyecto, es relevante ver cómo se hizo referencia solapada a la incapacidad relativa de los mapuche, por lo que el proyecto federal de Infante no hizo alusión alguna -hasta donde se ha revisado- a los pueblos primigenios, ignorándolos al interior de la conformación político-administrativa del nuevo régimen a aplicar. Quizás la actitud de Infante se justificaba en el decreto de Bernardo O'Higgins de 1819, que declaró a todos los habitantes del territorio como chilenos (Secretaría de Redacción 2007: 117-119).

En las discusiones posteriores se hizo referencia a las atribuciones y restricciones de las asambleas y del gobernador de provincia y otros funcionarios (Congreso Nacional 1889b, tomo XII: 244-246) ${ }^{78}$. En definitiva, tal como Infante declararía posteriormente en EVF $\mathrm{N}^{\circ} 32$ (pp. 1-4) del 19 de enero de 1830, él creía que el modelo de Estado unitario sólo habría nacido de los déspotas, y que personajes históricos como Danton, Marat y Robespierre habrían propiciado este sistema en Francia del siglo XVIII, lo que más tarde habría mantenido Napoleón Bonaparte, tal como lo señaló el EVF:

La unidad política era la quiera de Bonaparte, o más bien su medio favorito de procurar el despotismo, y con la palabra del grande imperio que tenía siempre en la boca, sofocó por espacio de trece años todas las resistencias locales", es decir, los esfuerzos de las provincias por su libertad (1830: 1-4).

\footnotetext{
$78 \quad$ Para ello se puede leer el texto completo del RPr. El territorio se divide en 8 provincias. Sesión $24^{a}, 27$ de julio de 1826, bajo la presidencia de José Ignacio Cienfuegos.
} 
A partir de lo anterior, Infante dejó entrever respecto a las asambleas provinciales que, dadas las circunstancias (ausencia del poder ejecutivo y del legislativo ${ }^{79}$ y con el ejército dividido en dos facciones), ellas debían hacerse representar con el objetivo de asegurar y preservar sus derechos adquiridos. Además, creía que sin estas asambleas la guerra civil podría seguir prolongándose debido a la falta de autonomía que se les estaba negando con los proyectos "liberticidas" con los que muchos "malvados" insistían en "monarquizar" a las nóveles repúblicas americanas. Para aportar con soluciones al ínterin gubernativo, Infante propondría asambleas legislativas en cada provincia por sobre el Congreso Nacional, el que les estaría despojando de tal potestad autónoma.

Durante el período de estudio, las discusiones posteriores a la Sesión $24^{a}$ hicieron alusión a una serie de vicisitudes que por ahora no corresponden a estas disquisiciones, pues dicen relación con otros manuscritos que se están trabajando. No obstante, conviene destacar que algunos de estos puntos tienen que ver con: la rebelión de Valdivia, Osorno y Chiloé que se formalizó el 19 de junio de 1826 y a menos de 5 años desde el motín de Osorno, así como lo que pasó con los sublevados de dicha rebelión; la conflictividad intelectual entre Juan Egaña y José Miguel Infante; las discusiones sobre la deuda a Londres de Portales, Cea y Cía.; o la anunciada invasión del ejército o'higginista nada menos que con su líder a la cabeza; además de las críticas que Infante hizo a la Constitución de 1828 acusándola de remedo del PCF

$79 \quad$ Recuérdese que entre el 24 de diciembre de 1829 y el 17 de febrero de 1830 en Chile gobernaba una Junta de Gobierno, cuyo presidente era José Tomás Ovalle, en la cual José Miguel Infante tenía esperanzas de nuevas albricias que facilitaran la instauración del federalismo como forma de Estado y de gobierno republicano. de 1826, leyendo entrelíneas los artículos que parecían suponerle más suspicacias y vendettas políticas que otra cosa.

Esta última crítica a la Constitución de 1828 sería muy relevante, porque efectivamente habría anulado esta Carta Fundamental si es que se hubiera respetado lo prescrito por la Ley Fundamental dada por el Congreso Nacional el 23 de enero de 1825, en su Art. 2, cuando se establece que: "por ahora y hasta la promulgación de la Constitución que ha de reorganizar el Estado, las provincias se regirán por sus propias instituciones", cosa que Infante recalcó que no se había cumplido, imponiéndose autoritariamente la Carta de 1828 (EVF 1830: N ${ }^{\circ}$ 38), la que sería la palada final de tierra para la inhumación del cadáver federalista en la nación austral americana.

Si bien Infante permaneció impertérrito en su postura ideológica, no es menor revelar que él mismo era miembro de la élite santiaguina, aunque acicateado -como se señaló en páginas anteriores- por ideas liberales heredadas de su tío José Antonio de Rojas, lector de Voltaire y de los demás enciclopedistas. Quizás también por eso mismo, cuando fue procurador de la Junta de Gobierno de 1810, pretendía convocar a elecciones para un congreso autónomo en Chile, adoptando el principio revolucionario de la soberanía popular, justamente en el período de mayor clímax autonomista. Más tarde, el centralismo y el exceso de autoritarismo del cargo de director supremo comenzaría a sacar de su fuero interno la lucha por las libertades.

Esto mismo, unido a la exclusión de la autonomía de las provincias (Coquimbo y Concepción), no sólo originaría el levantamiento de Freire contra O'Higgins (Illanes 1987), sino 
que significaría el impulso final para que Infante adhiriera a la causa regionalista como una consecuencia del poder despótico directorial y del abuso administrativo y sus atribuciones extraordinarias, optando por la desconfianza a la concentración del poder central (Valenzuela 2008), en un contexto donde el centralismo reinante habría excluido de la ilustración a las provincias más alejadas de Santiago, algo que el federalismo podía remediar (Stuven y Cid 2012).

Es esta lucha por la autonomía provincial, el deseo de inclusión y consideración nacido, paradójicamente, de la imposición que significaba la exclusión en la toma de decisiones políticas, administrativas y económicas relativas a las necesidades de las propias provincias aunque emanadas desde el centro, lo que José Miguel Infante decidió acoger a publicación en su periódico, haciendo notar la presencia de las provincias y su necesidad de cambios políticos. Es así como Infante llega a perfilarse como un crítico ácido que lucharía por expandir el federalismo y, junto con él, la inclusión en los negocios nacionales de las ocho provincias que habían nacido en el país, develando las injerencias del Estado central en ellas, así como las críticas de aquél al modelo unitario.
Por último, es dable decir que las iniciativas ensayadas antes del primer tercio del siglo XIX en pro del federalismo pretendían la creación de un puente o de una línea de comunicación directa entre el republicanismo y el liberalismo -como autogobierno provincial- (Jaksić y Serrano 2011; Barrón 2002), con la idea de evitar conflictos futuros que podrían afectar al conjunto social recientemente emancipado de la tutela española. Esta distensión habría estado propiciada por lo que Vasco Castillo (2009) ha recogido como republicanismo federalista, considerándolo el momento más "democrático" del republicanismo chileno, porque con él se pretendió fortalecer la participación de los ciudadanos como forma de garantizar la libertad de la propia república, previniendo gobiernos excesivamente autoritarios o despóticos ante la posible inapetencia política activa de los ciudadanos. Es por esto que las asambleas provinciales, así como el cabildo -una de las instituciones políticas más antiguas en América-, la elección de intendentes, gobernadores y curas párrocos (Carmagnani 1993), constituirían para las provincias una instancia más que prometedora para los intereses federalistas $\mathrm{y}$, de paso, fortalecerían -según las autoridades de la época- al gobierno republicano que intentaba consolidarse desde el centro de la nación.

\section{Bibliografía}

Achondo, B. 2006. Un hombre de Estado: Vida política del federalista chileno José Miguel Infante (1810-1844). Santiago de Chile: Ediciones PUC.

Aljovín, C. y Araya, E. 2005. "Prácticas políticas y formación de ciudadanía”. Chile-Perú, Perú-Chile: 1820-1920. Desarrollos políticos, económicos y culturales. Cavieres, E. (Ed.). Santiago de Chile: Ediciones Universitarias de Valparaíso. 101-138.

Backenkhöler, Ch. 2008. "El neorepublicanismo de Philip Pettit”. Pensamiento político contemporáneo. Una panorámica. Aguilera, R. y Escámez, S. (Eds.). México D.F.: Editorial Porrúa.
$1-27$.

Barrón, L. 2002. "Republicanismo, liberalismo y conflicto ideológico en la primera mitad del siglo XIX en América Latina". El republicanismo en Hispanoamérica. Ensayos de historia intelectual y política. Aguilar, J. A. y Rojas, R. (Coords.). México D.F.: FCE. 118-140.

Barros Arana, D. 2005. Historia general de Chile. Tomo XIV. Santiago de Chile: Editorial Universitaria.

Blest Gana, A. 1861. "Literatura chilena. Algunas consideraciones sobre ella". Anales de la Universidad de Chile. Dis- 
ponible en: http://www.anales.uchile.cl/index.php/ANUC/article/ viewArticle/3177 (consultado en enero de 2014).

Carmagnani, M. 1993. "Conclusión: El federalismo, historia de una forma de gobierno". Federalismos latinoamericanos: México / Brasil / Argentina. Carmagnani, M. (Coord.). México D. F.: FCE. 397-416.

Castillo, V. 2009. La creación de la República. La filosofía pública en Chile 1810-1830. Santiago de Chile: LOM.

Cattaneo, I. 2013. Los impuestos fiscales a las rentas agrícolas en el siglo XIX. Memoria para optar al grado de Licenciado en Ciencias Jurídicas y Sociales. Santiago de Chile: Facultad de Derecho, Departamento de Ciencias del Derecho, Universidad de Chile.

Chiaramonte, J. et al. 1995. "Vieja y nueva representación: Los procesos electorales en Buenos Aires, 1810-1820". Historia de las elecciones en Iberoamérica, siglo XIX. Annino, A. (Coord.). Buenos Aires: FCE. 19-63.

Congreso Nacional. S/F. Reseñas Biográficas Parlamentarias (RBP). Santiago: Biblioteca del Congreso Nacional de Chile. Disponible en: http://historiapolitica.bcn.cl/resenas_parlamentarias (consultado en mayo de 2014).

1889a. Sesiones de los Cuerpos Lejislativos de la República de Chile. Tomo VII. Letelier, V. (Recop.). Santiago de Chile: Imprenta Cervantes.

1889b. Sesiones de los Cuerpos Lejislativos de la República de Chile. Tomo XII. Letelier, V. (Recop.). Santiago de Chile: Imprenta Cervantes.

1889c. Sesiones de los Cuerpos Lejislativos de la República de Chile. Tomo XIV. Letelier, V. (Recop.). Santiago de Chile: Imprenta Cervantes.

Delgado, H., Gallardo, E. y Lespai, J. 2007. Amotinados, abigeos y usurpadores. Una mirada regional acerca de las formas de violencia en Osorno (1821-1931). Osorno: Universidad de Los Lagos-PEDCH.

Departamento de Estado de Estados Unidos. S/F. "E camino de la independencia". Programas de información internacional. Disponible en: http://usinfo.state.gov (consultado en enero de 2014).

Elazar, D. 1990. Exploración del federalismo. Barcelona: Editorial Hacer.

Elgueta, E. 1986. El federalismo. Santiago de Chile:

Ediciones PUCV.

Erlbaum, J. 1964. El federalismo en Chile, 1826-1827. Santiago de Chile: Editorial PUC.

Fernández, M. 2009. "Chile. Capítulo 9: Pueblo / Pueblos". Diccionario político y social del mundo Iberoamericano. La era de las revoluciones, 1750-1850. Fernández, J. (Dir.). Madrid: Centro de Estudios Políticos y Constitucionales. 1163-1176.

Fleet, N. 2009. "Razón y dominación. La legitimidad en Weber como orientación simbólica de la acción política". Revista Austral de Ciencias Sociales 16: 21-36.

Guerra, A. 2014. Pensar como no se debe: Las ideas en crisis. Conspiradores e ilustrados en Santiago de Chile (17801810). Valparaíso: Ediciones Universitarias de Valparaíso.

Guerra, F. X. 2002. "El soberano y su reino. Reflexiones sobre la génesis del ciudadano en América Latina". Ciudadanía política y formación de las naciones. Perspectivas históricas de América Latina. Sábato, H. (Coord.). México D. F.: FCE. 33-61.

Gumucio, R. 2003. "Utopías libertarias en Chile, siglos XIX y XX". Polis, Revista Latinoamericana 6: 2-20.

Illanes, M. 1987. "Del mito patriótico al positivismo militar". El pensamiento en Chile 1830-1910. Berríos, M. et al. (Autores). Santiago de Chile: Nuestra América Ediciones. 27-43. Infante, J. 1827. "Reglamento Provisorio para el Régimen de las Provincias (RPr)". Latin American Pamphlet, Digital Collection, Harvard University, Collection Development Departament, Widener Library en HCL / Chile. Santiago de Chile: Imprenta de la Biblioteca. 1-6.

Instituto Nacional de Estadísticas. 1835. Repertorio chileno. Santiago de Chile: INE.

Jaksić, I. y Serrano, S. 2011. "El gobierno y las libertades. La ruta del liberalismo chileno en el siglo XIX". Liberalismo y poder. Latinoamérica en el siglo XIX. Jaksić, I. y Serrano, S. (Eds.). Santiago de Chile: FCE. 177-206.

Laborde, M. 2008. "Historia de las ideas en torno al lugar de los pobres en la ciudad". La pobreza en Chile. Tomo II. Santiago de Chile: Anales del Instituto de Chile. 157-180.

Leal, C. 2009. "Chile. Capítulo 4: Federación / Federalismo". Diccionario político y social del mundo Iberoamericano. La era de las revoluciones, 1750-1850. Fernández, J. (Dir.). Madrid: Centro de Estudios Políticos y Constitucionales. 425-450.

Lesser, R. 2006. La América española. De la utopía al estadillo. Buenos Aires: Longseller.

Mascareño, C. 2011. "Representación y participación ¿Modelos de democracia contrapuestos en América Latina?”. Democracia participativa vs representación. Tensiones en América Latina. Mascareño, C. y Montecinos, E. (Coords.). Caracas: Universidad de Los Lagos-CEDER/CENDES. 183-209.

McFarlane, A. 2009. "La caída de la monarquía española y la independencia hispanoamericana". Las independencias hispanoamericanas. Interpretaciones 200 años después. Palacios, M. (Coord.). Bogotá: Editorial Norma. 31-59.

Morelli, F. 2006. "José Carlos Chiaramonte. Nación y Estado en Iberoamérica. El lenguaje político en tiempos de la independencia". Nuevo Mundo Mundos Nuevos, Comptes rendus et essais historiographiques. Disponible en: http://nuevomundo. revues.org/1734 (consultado en junio de 2013).

Oszlak, Ó. 1997. La formación del Estado argentino: Orden, progreso y organización nacional. Buenos Aires: Editorial Planeta.

Paredes, F. 2013. "¿Por qué es necesario plantear el federalismo como una alternativa a la desigualdad en Chile?". Igualdad, inclusión y derecho. Lo político, lo social y lo jurídico en clave igualitaria. Muñoz, F. (Ed.). Santiago de Chile: LOM. 115-126. de Chile: LOM.

Pinto, J. y Valdivia, V. 2009. ¿Chilenos todos? Santiago

Pinto Rodríguez, J. 2003. La formación del Estado y la nación, y el pueblo mapuche. De la inclusión a la exclusión. Santiago de Chile: DIBAM.

S/A. 1910. Colección de historiadores i de documentos relativos a la independencia de Chile. Tomo XVIII. Santiago de Chile: Imprenta Cervantes. 
Salazar, G. 2005. Construcción de Estado en Chile (1800-1837). Democracia de los "pueblos". Militarismo ciudadano. Golpismo oligárquico. Santiago de Chile: Editorial Sudamericana. S/F. Cuando los pobres son protagonistas. Santiago de Chile: Centro de Estudios Miguel Enríquez. y Pinto, J. 1999. Historia contemporánea de Chile. Estado, legitimidad y ciudadanía. Volumen I. Santiago de Chile: LOM.

Santa María, D. 1853. Vida de Don José Miguel Infante. Santiago de Chile: S.D.E.

Secretaría de Redacción. 2007. "Decreto de Director Supremo B. O'Higgins eximiendo del tributo a los indígenas y otorgándoles la ciudadanía. 1819". Espacio Regional 1 (4): 117-119.

Sotelo, I. 2004. "Estado Moderno". Filosofía política II. Teoría del Estado. Díaz, E. y Ruiz, A. (Eds.). Madrid: Editoria Trotta. 25-44.
Stuven, A. M. y Cid, G. 2012. Debates republicanos en Chile. Siglo XIX. Volumen I. Santiago de Chile: Ediciones Universidad Diego Portales.

Urbina, M. 2009. La frontera de arriba en Chile colonial. Interacción hispano-indígena en el territorio entre Valdivia y Chiloé e imaginario de sus bordes geográficos, 1600-1800. Santiago de Chile: Centro de Investigaciones Diego Barros Arana.

Valenzuela, E. 2008. La voz terrible. Infante y El Valdiviano Federal. Santiago de Chile: Editorial Universidad Bolivariana.

et al. 2003. El fantasma federal en Chile: La potencia de la reforma regional. Santiago de Chile: FES-UNIR.

Velasco, G. 2012. "Prólogo". El Federalista. Hamilton, A., Madison, J. y Jay, J. (Autores). México D. F.: FCE. VIII-IX. Zambrano, E. 1999. El ensayo federalista de 1826-27. Santiago de Chile: Editorial PUCV. 
